\title{
A Divergence-Based Medical Decision-Making Process of COVID-19 Diagnosis
}

\author{
Bahram Farhadinia \\ Department of Mathematics, Quchan University of Technology, Quchan, Iran \\ Correspondence should be addressed to Bahram Farhadinia; bfarhadinia@qiet.ac.ir
}

Received 3 December 2021; Revised 12 January 2022; Accepted 18 January 2022; Published 11 February 2022

Academic Editor: Ali Ahmadian

Copyright ( 92022 Bahram Farhadinia. This is an open access article distributed under the Creative Commons Attribution License, which permits unrestricted use, distribution, and reproduction in any medium, provided the original work is properly cited.

\begin{abstract}
This study is concerned with introducing a class of parametric and symmetric divergence measures under hesitant fuzzy environment. The proposed divergence measures have several interesting properties which make their use attractive. In order for exploring the features of proposed divergence measures for hesitant fuzzy sets (HFSs), we compare them with other existing ones in terms of divergence-initiated weighs and counter-intuitive cases. In the process of comparison, we first modify the conventional framework of hesitant fuzzy additive ratio assessment (HFARAS) using the proposed divergence measures, and then, the superiority of proposed measures is further demonstrated in a COVID-19 case study. There, we notify that the other existing divergence measures may not provide satisfactory results.
\end{abstract}

\section{Introduction}

These days, the COVID-19 pandemic is drastically impacting healthcare systems [1-3] worldwide. To solve the problems of this pandemic, many medical scientists are focusing their research on that, and for recognizing and diminishing the COVID-19 effects, a large number of researchers have prepared a variant of workable models. Fouladi et al. [4] considered ResNet, OxfordNet, convolutional neural network, convolutional autoencoder neural network, and machine learning methods in order to classify chest CT images of COVID-19. Melin et al. [5] predicted successfully the consequence of COVID-19 time series by the help of a multiple collaborative convolutional neural network tool which is described thoroughly by encountering the concept of fuzzy set. Abdel-Basst et al. [6] merged two techniques, namely, the Best-Worst Method (BWM) and Technique for Order Preference by Similarity to Ideal Solution (TOPSIS) method to explore the association between COVID-19 and different viral chest diseases in uncertainty environment. By implementation of a model of Internetbased reporting, Bonilla-Aldana et al. [7] gathered the data on COVID-19 to increase its effectiveness during the pandemic. Ashraf and Abdullah [8] proposed a number of tools for dealing with the emergency condition of COVID-19 using the concept of spherical fuzzy set. In the period of COVID-19 pandemic in China, Wu et al. [9] introduced a technique to plan several emergency production procedures for producing a proper medical mask. Mishra et al. [10] enhanced the additive ratio assessment model by encountering the divergence measure to evaluate the medicine being used to treat those patients involving the mild symptoms of COVID-19.

The additive ratio assessment (ARAS) technique [11] implements the concept of optimality degree for extracting a ranking. In brief, this technique is described as a fraction of two values: the sum of normalized weighted values for criteria corresponding to each alternative and the sum of normalized weighted values for the best alternative. Indeed, the ARAS framework has intuitive procedures yielding relatively exact outcomes in the process of choosing diversified alternatives.

Up to now, there exist a large number of fuzzy-based contributions dedicated to the ARAS technique. Following, Zavadskas and Turskis [11] who first argued that a complicated phenomenon in the real world could be realized by the help of simple comparisons, Turskis and Zavadskas [12] tried to select the logistic center location based on the 
combination of AHP and ARAS for data in the form of fuzzy sets. In the sequel, Stanujkic [13] generalized the ARAS framework to that of interval-valued fuzzy sets. Büyüközkan and Göçer [14] developed the ARAS framework to that of interval-valued intuitionistic fuzzy sets for evaluating the digital supply chains. Büyüközkan and Göçer [15] assessed the digital maturity scores of the firms on the basis of hesitant fuzzy ARAS framework. Iordache et al. [16] suggested an interval type II hesitant fuzzy ARAS framework for choosing the location of underground hydrogen storage. Liao et al. [17] offered an ARAS framework encountering the hesitant fuzzy linguistic term data to choose a digital finance supplier selection.

The technique of ASAS yields benefits which are association with criteria weights proportionally and straightly [11], scalability and flexibility $[13,14]$, and adaptability to various fuzzy environments [14]. It also yields weaknesses which are behaviour dependency on the different levels of knowledge elicited by decision makers [14] and behaviour dependency on given data-type of participants [18].

Divergence measure is generally used to quantify the distance between two distributions by evaluating the amount of their discrimination. There exist a set of diverse contributions which deal with the divergence applications in the context of research framework, especially the field of multiple criteria decision making.

In order to show the applicability of divergence measure under a hesitant fuzzy environment in which the criteria weights are to be computed in terms of the Shapley function, Mishra et al. [19] investigated the problem of service quality decision making. Then, Mishra et al. [19] offered another exponential HFS divergence measure to assess the green supplier problem. Furthermore, Mishra et al. [10] developed an ARAS technique by encountering a divergence-based procedure for assessing rationally the relative importance of criteria. In the sequel, Mishra et al. [20] defined a parametric hesitant fuzzy-based divergence measure for evaluating the criteria weights.

In any way, the weight determination process of criteria has a remarkable impact on the decision outcomes, and the divergence measure is a factor which plays an important role in the determination of criteria weight. As shown in Section 5, the abovementioned HFS divergence measures are limited in nature. Therefore, we have been in search of new divergence measures with fewer drawbacks.

In summary, the major distinctive features of the study are as follows:

(1) It introduces an innovative class of divergence measures for HFSs which are parametric and symmetric

(2) A number of interesting properties of proposed divergence measure are proved and discussed

(3) This contribution reviews and explores counter-intuitive cases of existing divergence measures under hesitant fuzzy environment

(4) The experimental results demonstrate that the parametric hesitant fuzzy divergence measure is more effective than the existing ones in decisionmaking situations

This contribution is set up as follows. We first recall the concept of HFS, and a brief review of some preliminaries is given in Section 2. In Section 3, an innovative class of hesitant fuzzy divergence measures is introduced parametrically and symmetrically. We modify the existing framework of hesitant fuzzy ARAS (HFARAS) using the proposed divergence measures in Section 4. Section 5 is devoted to present the application of proposed divergence measures in a case study of COVID-19 coronavirus. Finally, several conclusions are drawn in Section 6.

\section{Preliminaries to Hesitant Fuzzy Sets (HFSs)}

In this section, we review some basic notions and wellknown results about HFSs that are used in the next discussion.

Let $X$ be the reference set. A hesitant fuzzy set (HFS) on $X$ is defined by Torra [21] in terms of a function that when it is applied to $X$, it returns a subset of $[0,1]$.

In fact, the notion of HFS is employed for handling a class of decision-making problems where the belongingness degree of an element to a set includes a variety of values.

Toward a better understanding, Xia and $\mathrm{Xu}$ [22] reconsidered the concept of HFS in the form of

$$
H_{A}=\left\{\left\langle x, h_{A}(x)\right\rangle: x \in X\right\},
$$

where $h_{A}(x)$ stands for all possible membership degrees of $x \in X$ belonging to the set $H_{A}$, and it is afterwards named as the hesitant fuzzy element (HFE) of $H_{A}$.

Adding to the latter presented concept are the following set and arithmetic operations. Let $h_{1}=\left\{h_{1}^{\delta(i)} \mid i=1, \ldots, l_{h_{1}}\right\}$ and $h_{2}=\left\{h_{2}^{\delta(i)} \mid i=1, \ldots, l_{h_{2}}\right\}$ be two HFEs. Then, it is defined (i.e., [23]).

(i) Complement: $h_{1}^{c}=\cup_{h_{1}^{\delta(i)} \in h_{1}}\left\{1-h_{1}^{\delta(i)}\right\}$

(ii) Union: $h_{1} \cup h_{2}=\cup_{h_{1}^{\delta(i)} \in h_{1}, h_{2}^{\delta(j)} \in h_{2}}\left\{\max \left\{h_{1}^{\delta(i)}, h_{2}^{\delta(j)}\right\}\right\}$

(iii) Intersection: $h_{1} \cap h_{2}=\cup_{h_{1}^{\delta(i)} \in h_{1}, h_{2}^{\delta(j)} \in h_{2}}\left\{\min \left\{h_{1}^{\delta(i)}, h_{2}^{\delta(j)}\right\}\right\}$

(iv) Addition: $h_{1} \oplus h_{2}=\cup_{h_{1}^{\delta(i)} \in h_{1}, h_{2}^{\delta(j)} \in h_{2}}\left\{h_{1}^{\delta(i)}+h_{2}^{\delta(j)}-h_{1}^{\delta(i)} h_{2}^{\delta(j)}\right\}$

(v) Multiplication: $h_{1} \otimes h_{2}=\cup_{h_{1}^{\delta(i)} \in h_{1}, h_{2}^{\delta(j)} \in h_{2}}\left\{h_{1}^{\delta(i)} h_{2}^{\delta(j)}\right\}$

(vi) Multiplication by scalar: $\lambda h_{1}=\cup_{h_{1}^{\delta(i)} \in h_{1}}$ $\left\{1-\left(1-h_{1}^{\delta(i)}\right)^{\lambda}\right\}, \quad \lambda>0$

(vii) Power: $h_{1}^{\lambda}=\cup_{h_{1}^{\delta(i)} \in h_{1}}\left\{\left(h_{1}^{\delta(i)}\right)^{\lambda}\right\}, \quad \lambda>0$

We explain below how the total ordering on HFEs was proposed and introduced. This was achieved by keeping in mind the score function of $h=\left\{h^{\delta(i)} \mid i=1, \ldots, l_{h}\right\}$ given by [22]

$$
s(h)=\frac{1}{l_{h}} \sum_{i=1}^{l_{h}} h^{\delta(i)}
$$

and its variance function [24] is defined by the following formulation: 


$$
v(h)=\frac{2 \cdot\left(l_{h}-2\right)}{l_{h} !} \sqrt{\sum_{h^{\delta(i)}, h^{\delta(j)} \in h}\left(h^{\delta(i)}-h^{\delta(j)}\right)^{2}} .
$$

Indeed, the total ordering of HFEs $h_{1}=\left\{h_{1}^{\delta(i)} \mid i=1, \ldots, l_{h_{1}}\right\}$ and $h_{2}=\left\{h_{2}^{\delta(i)} \mid i=1, \ldots, l_{h_{2}}\right\}$ could be defined by using the following comparison scheme:

(i) If we have $s\left(h_{1}\right)<s\left(h_{2}\right)$, then it is concluded that $h_{1} \prec_{T} h_{2}$

(ii) If we have $s\left(h_{1}\right)<s\left(h_{2}\right)$, then

(i) For the relation $v\left(h_{1}\right)<v\left(h_{2}\right)$, we get $h_{1} \prec_{T} h_{2}$

(ii) For $v\left(h_{1}\right)=v\left(h_{2}\right)$, we conclude that $h_{1} \approx{ }_{T} h_{2}$

Now, we are in a position to explain the unified length scale of HFSs as follows: in most situations, we observe that $l_{h_{1}} \neq l_{h_{2}}$. In order for comparing $h_{1}$ and $h_{2}$ correctly, we may extend the shorter HFE until the length of both HFEs are the same [25-28]. Suppose that $l=\max \left\{l_{h_{1}}, l_{h_{2}}\right\}$. Then, the shorter HFE is extended by appending the same value repeatedly. The repeated value depends on the risk preference of the decision makers, that is, if we consider (i) the pessimistic case, then the repeated value is the shortest one; (ii) if the optimistic case is considered, then the largest value will be repeated, and (iii) in the general case, we consider the convex combination of maximum and minimum values of a HFE.

Suppose that $h_{1}=\left\{h_{1}^{\delta(j)} \mid j=1, \ldots, l\right\} \quad$ and $h_{2}=\left\{h_{2}^{\delta(j)} \mid j=1, \ldots, l\right\}$ are two length-unified HFEs on $X$. The elementwise ordering of HFEs is defined by (i.e., [29])

$$
h_{1} \leq{ }_{E} h_{2} \text { if and only if } h_{1}^{\delta(j)} \leq h_{2}^{\delta(j)},
$$

for any $j=1, \ldots, l$.

Eventually, we represent the definition of two widely used aggregation operators of HFEs [25, 29]. Let $h_{1}=\left\{h_{1}^{\delta(j)} \mid j=1, \ldots, l\right\}, \quad h_{2}=\left\{h_{2}^{\delta(j)} \mid j=1, \ldots, l\right\}, \quad$ and $h_{m}=\left\{h_{m}^{\delta(j)} \mid j=1, \ldots, l\right\}$ be a set of $m$ HFEs with the corresponding weights $\varpi_{i}(i=1, \ldots, m)$. Then, it is defined. (i) The hesitant fuzzy weighted averaging (HFWA) operator:

$$
\begin{aligned}
\operatorname{HFWA}\left(h_{1}, h_{2}, \ldots, h_{m}\right) & =\underset{i=1}{m}\left(\oplus_{i} h_{i}\right) \\
& =\left\{1-\prod_{i=1}^{m}\left(1-h_{i}^{\sigma(j)}\right)^{\Phi_{i}} \mid j=1, \ldots, l\right\} .
\end{aligned}
$$

(ii) The hesitant fuzzy weighted geometric (HFWG) operator:

$$
\begin{aligned}
& \operatorname{HFWG}\left(h_{1}, h_{2}, \ldots, h_{m}\right)=\underset{i=1}{\stackrel{m}{\otimes}}\left(h_{i}^{\Phi_{i}}\right) \\
& =\left\{\prod_{i=1}^{m}\left(h_{i}^{\sigma(j)}\right)^{\Phi_{i}} \mid j=1, \ldots, l\right\} .
\end{aligned}
$$

\section{A New Class of HFS Divergence Measures}

Axiomatically, a divergence measure of two HFSs satisfies the following items similar to that of fuzzy sets [30] and intuitionistic fuzzy sets [31]:

(i) It is nonnegative and symmetric

(ii) It returns the zero value whenever the two sets coincide

In this contribution, we are going to develop a procedure that estimates the objective weights of criteria by using the concept of divergence measure, needless to say that the criteria weights are computed subjectively or objectively. The former technique computes the criteria weights by taking the thought of decision makers, while the latter technique characterizes the criteria weights by considering the mathematical assessments.

Let $h_{1}=\left\{h_{1}^{\delta(j)} \mid j=1, \ldots, l\right\}$ and $h_{2}=\left\{h_{2}^{\delta(j)} \mid j=1, \ldots, l\right\}$ be two length-unified HFEs as described above.

The following formula introduces a class of innovative divergence measures for HFSs:

$$
\operatorname{Div}_{\Gamma}\left(h_{1}, h_{2}\right)=\frac{1}{l} \sum_{j=1}^{l}\left[\left(\frac{\gamma_{1} \Gamma\left(h_{1}^{\delta(j)}\right)+\gamma_{2} \Gamma\left(h_{2}^{\delta(j)}\right)}{\gamma_{1}+\gamma_{2}}\right)-\Gamma\left(\frac{\gamma_{1} h_{1}^{\delta(j)}+\gamma_{2} h_{2}^{\delta(j)}}{\gamma_{1}+\gamma_{2}}\right)\right],
$$

where $\Gamma$ is a real convex function, and $\gamma_{k}(k=1,2)$ are the positive and real numbers.

Among all the real convex functions, $\Gamma$ may be chosen as follows:
(i) $\Gamma(h)=p_{1} h+p_{2}$ for $p_{1}, p_{2} \in \Re$ (affine function)
(ii) $\Gamma(h)=\exp (p h)$ for $p \in \mathfrak{R}$ (exponential function)
(iii) $\Gamma(h)=h^{p}$ for $p \geq 1$ (power function)

(iv) $\Gamma(h)=|h|^{p}$ for $p \geq 1$ (absolute-value function)

(v) $\Gamma(h)=-\log (h)$ (logarithmic function)

(vi) $\Gamma(h)=h \times \log (h)$ (combinatorial function)

To simplify the next discussion, hereafter, we only restrict $\Gamma$ by its power type $\Gamma(h)=h^{p}$ for $p \geq 1$ together with $\gamma_{1}=\gamma_{2}=1$. In view of this, we attain the following class of divergence measures for HFSs: 


$$
\operatorname{Div}_{\Gamma}\left(h_{1}, h_{2}\right)=\frac{1}{l} \sum_{j=1}^{l}\left[\left(\frac{\left(h_{1}^{\delta(j)}\right)^{p}+\left(h_{2}^{\delta(j)}\right)^{p}}{2}\right)-\left(\frac{h_{1}^{\delta(j)}+h_{2}^{\delta(j)}}{2}\right)^{p}\right], \quad p \geq 1 .
$$

Remark 1. It is interesting to note that the measure Div given by (8) will be the divergence measure of Mishra et al. [10] if we set $p=2$.

Before presenting the main properties of divergence measure $\operatorname{Div}_{\Gamma}$ given by (8), we are going to state the following lemma.

Lemma 1. Assume that $h_{j} \geq 0$ for any $1 \leq j \leq n$. Then, it holds that

$$
\sum_{j=1}^{n}\left(h_{j}\right)^{p} \leq\left(\sum_{j=1}^{n} h_{j}\right)^{p} \leq n^{p-1} \sum_{j=1}^{n}\left(h_{j}\right)^{p}, \quad p \geq 1 .
$$

Proof. To prove the left-hand inequality, we set $H:=\sum_{j=1}^{n} h_{j}$ and $H_{j}:=h_{j} / H$. Then, we easily find that $0 \leq H_{j} \leq 1$ together with $\sum_{j=1}^{n} H_{j}=1$. Now, from the fact that $\left(H_{j}\right)^{p} \leq H_{j}$ for any $p \geq 1$, we conclude that $\sum_{j=1}^{n}\left(H_{j}\right)^{p} \leq \sum_{j=1}^{n} H_{j}=1$. This implies that $\sum_{j=1}^{n}$ $\left(H_{j}\right)^{p}=\sum_{j=1}^{n}\left(h_{j} / H\right)^{p} \leq 1$, and therefore, $\sum_{j=1}^{n}\left(h_{j}\right)^{p}$ $\leq H^{p}=\left(\sum_{j=1}^{n} h_{j}\right)^{p}$.

To prove the right-hand inequality, we apply Jensen's inequality

$$
\Gamma\left(\frac{\sum_{j=1}^{n} \gamma_{j} h_{j}}{\sum_{j=1}^{n} \gamma_{j}}\right) \leq \frac{\sum_{j=1}^{n}\left(\gamma_{j} \Gamma\left(h_{j}\right)\right)}{\sum_{j=1}^{n} \gamma_{j}}
$$

to $\Gamma(x)=x^{p}$ with $\gamma_{1}=\cdots=\gamma_{n}=1 / n$. Thus, we conclude that $\left(1 / n \sum_{j=1}^{n} h_{j}\right)^{p} \leq \sum_{j=1}^{n} 1 / n\left(h_{j}\right)^{p}$, which implies that $\left(\sum_{j=1}^{n} h_{j}\right)^{p} \leq n^{p-1} \sum_{j=1}^{n}\left(h_{j}\right)^{p}$.

Now, we establish the fundamental aim of this study which is given by the following theorem.

Theorem 1. Suppose that $h_{1}=\left\{h_{1}^{\delta(j)} \mid j=1, \ldots, l\right\}$ and $h_{2}=$ $\left\{h_{2}^{\delta(j)} \mid j=1, \ldots, l\right\}$ are two length-unified HFEs. Then, the formula Div $v_{\Gamma}\left(h_{1}, h_{2}\right)$ given by (8) presents a divergence measure for any $p \geq 1$.

Proof. It needs to show that the formula $\operatorname{Div}_{\Gamma}\left(h_{1}, h_{2}\right)$ satisfies the two items given in the beginning of this section, that is, for any two HFEs $h_{1}=\left\{h_{1}^{\delta(j)} \mid j=1, \ldots, l\right\}$ and $h_{2}=\left\{h_{2}^{\delta(j)} \mid j=1, \ldots, l\right\}$, it must be held that

$$
\begin{gathered}
\operatorname{Div}_{\Gamma}\left(h_{1}, h_{2}\right) \geq 0 ; \\
\operatorname{Div}_{\Gamma}\left(h_{1}, h_{2}\right)=0 \text { if and only if } h_{1} \approx{ }_{E} h_{2} .
\end{gathered}
$$

The proof of relation (11): from Lemma 1, we find that $\left(\sum_{k=1}^{2} h_{k}^{\delta(j)}\right)^{p} \leq 2^{p^{-1}} \sum_{k=1}^{2}\left(h_{k}^{\delta(j)}\right)^{p}$ is true for any $j=1, \ldots, l$. Equivalently,

$$
\left(\frac{h_{1}^{\delta(j)}+h_{2}^{\delta(j)}}{2}\right)^{p} \leq \frac{\left(h_{1}^{\delta(j)}\right)^{p}+\left(h_{2}^{\delta(j)}\right)^{p}}{2}
$$

holds true for any $j=1, \ldots, l$, and hence,

$$
\operatorname{Div}_{\Gamma}\left(h_{1}, h_{2}\right)=\frac{1}{l} \sum_{j=1}^{l}\left[\left(\frac{\left(h_{1}^{\delta(j)}\right)^{p}+\left(h_{2}^{\delta(j)}\right)^{p}}{2}\right)-\left(\frac{h_{1}^{\delta(j)}+h_{2}^{\delta(j)}}{2}\right)^{p}\right] \geq 0, \quad \text { for any } p \geq 1
$$

The proof of relation (12): assume that $h: \approx{ }_{E} h_{1} \approx{ }_{E} h_{2}$ which means that $h^{\delta(j)}:=h_{1}^{\delta(j)}=h_{2}^{\delta(j)}$ for any $j=1, \ldots, l$. Therefore,

$\operatorname{Div}_{\Gamma}(h, h)=\frac{1}{l} \sum_{j=1}^{l}\left[\left(\frac{\left(h^{\delta(j)}\right)^{p}+\left(h^{\delta(j)}\right)^{p}}{2}\right)-\left(\frac{h^{\delta(j)}+h^{\delta(j)}}{2}\right)^{p}\right]=0$.

Conversely, we suppose that $\operatorname{Div}_{\Gamma}\left(h_{1}, h_{2}\right)=0$, that is,

$\frac{1}{l} \sum_{j=1}^{l}\left[\left(\frac{\left(h_{1}^{\delta(j)}\right)^{p}+\left(h_{2}^{\delta(j)}\right)^{p}}{2}\right)-\left(\frac{h_{1}^{\delta(j)}+h_{2}^{\delta(j)}}{2}\right)^{p}\right]=0$,

for any $p \geq 1$. This implies that

$$
\left(\frac{\left(h_{1}^{\delta(j)}\right)^{p}+\left(h_{2}^{\delta(j)}\right)^{p}}{2}\right)-\left(\frac{h_{1}^{\delta(j)}+h_{2}^{\delta(j)}}{2}\right)^{p}=0
$$

for any $j=1, \ldots, l$.
The latter equality is possible if and only if the equalities $h_{1}^{\delta(j)}=h_{2}^{\delta(j)}(j=1, \ldots, l)$ hold true. This finding implies that $h_{1} \approx{ }_{E} h_{2}$.

Theorem 2. Suppose that $h_{1}=\left\{h_{1}^{\delta(j)} \mid j=1, \ldots, l\right\}, \quad h_{2}=$ $\left\{h_{2}^{\delta(j)} \mid j=1, \ldots, l\right\}$, and $h_{3}=\left\{h_{3}^{\delta(j)} \mid j=1, \ldots, l\right\}$ are three length-unified HFEs, and the formula $\operatorname{Div}_{\Gamma}\left(h_{1}, h_{2}\right)$ given by (8) presents a divergence measure. Then, for any $h_{1} \prec{ }_{E} h_{2} \prec{ }_{E} h_{3}$, the following inequalities hold true:

$$
\begin{aligned}
& \operatorname{Div}_{\Gamma}\left(h_{1}, h_{2}\right) \leq \operatorname{Div}_{\Gamma}\left(h_{1}, h_{3}\right) ;, \\
& \operatorname{Div}_{\Gamma}\left(h_{1}, h_{3}\right) \leq \operatorname{Div}_{\Gamma}\left(h_{2}, h_{3}\right) .
\end{aligned}
$$

Proof. Referring to the definition of elementwise ordering of HFEs given by (4), we observe that $h_{1} \leq_{E} h_{2} \leq_{E} h_{3}$ is valid if and only if $h_{1}^{\delta(j)} \leq h_{2}^{\delta(j)} \leq h_{3}^{\delta(j)}$ for any $j=1, \ldots, l$. Therefore, for any $p \geq 1$, we have 


$$
\begin{aligned}
\operatorname{Div}_{\Gamma}\left(h_{1}, h_{2}\right) & =\frac{1}{l} \sum_{j=1}^{l}\left[\left(\frac{\left(h_{1}^{\delta(j)}\right)^{p}+\left(h_{2}^{\delta(j)}\right)^{p}}{2}\right)-\left(\frac{h_{1}^{\delta(j)}+h_{2}^{\delta(j)}}{2}\right)^{p}\right] \\
& \leq \frac{1}{l} \sum_{j=1}^{l}\left[\left(\frac{\left(h_{1}^{\delta(j)}\right)^{p}+\left(h_{3}^{\delta(j)}\right)^{p}}{2}\right)-\left(\frac{h_{1}^{\delta(j)}+h_{3}^{\delta(j)}}{2}\right)^{p}\right]=\operatorname{Di} v_{\Gamma}\left(h_{1}, h_{3}\right),
\end{aligned}
$$

and

$$
\begin{aligned}
\operatorname{Div}_{\Gamma}\left(h_{1}, h_{3}\right) & =\frac{1}{l} \sum_{j=1}^{l}\left[\left(\frac{\left(h_{1}^{\delta(j)}\right)^{p}+\left(h_{3}^{\delta(j)}\right)^{p}}{2}\right)-\left(\frac{h_{1}^{\delta(j)}+h_{3}^{\delta(j)}}{2}\right)^{p}\right] \\
& \leq \frac{1}{l} \sum_{j=1}^{l}\left[\left(\frac{\left(h_{2}^{\delta(j)}\right)^{p}+\left(h_{3}^{\delta(j)}\right)^{p}}{2}\right)-\left(\frac{h_{2}^{\delta(j)}+h_{3}^{\delta(j)}}{2}\right)^{p}\right] \\
& =\operatorname{Div}_{\Gamma}\left(h_{1}, h_{3}\right) .
\end{aligned}
$$

Theorem 3. Suppose that $h_{1}=\left\{h_{1}^{\delta(j)} \mid j=1, \ldots, l\right\}$, $h_{2}=\left\{h_{2}^{\delta(j)} \mid j=1, \ldots, l\right\}$, and $h_{3}=\left\{h_{3}^{\delta(j)} \mid j=1, \ldots, l\right\}$ are three length-unified HFEs, and the formula $\operatorname{Div}_{\Gamma}\left(h_{1}, h_{2}\right)$ given by
(8) presents a divergence measure. Then, the following equalities hold true:

$$
\begin{aligned}
\operatorname{Div}_{\Gamma}\left(h_{1} \cup h_{2}, h_{1} \cap h_{2}\right)= & \operatorname{Div}_{\Gamma}\left(h_{1}, h_{2}\right), \\
\operatorname{Div}_{\Gamma}\left(h_{1} \cup h_{2}, h_{3}\right)= & \frac{1}{2}\left(\operatorname{Div}_{\Gamma}\left(h_{1}, h_{3}\right)\right. \\
& \left.+\operatorname{Div}_{\Gamma}\left(h_{2}, h_{3}\right)\right), \\
\operatorname{Div}_{\Gamma}\left(h_{1} \cap h_{2}, h_{3}\right)= & \frac{1}{2}\left(\operatorname{Div}_{\Gamma}\left(h_{1}, h_{3}\right)\right. \\
& \left.+\operatorname{Div}_{\Gamma}\left(h_{2}, h_{3}\right)\right) .
\end{aligned}
$$

Proof. For any $j=1, \ldots, l$ and $p \geq 1$, we propose the following proofs.

The proof of relation (21):

$$
\begin{aligned}
\operatorname{Div}_{\Gamma}\left(h_{1} \cup h_{2}, h_{1} \cup h_{2}\right) & =\frac{1}{l} \sum_{j=1}^{l}\left[\left(\frac{\left(\left(h_{1} \cup h_{2}\right)^{\delta(j)}\right)^{p}+\left(\left(h_{1} \cup h_{2}\right)^{\delta(j)}\right)^{p}}{2}\right)-\left(\frac{\left(h_{1} \cup h_{2}\right)^{\delta(j)}+\left(h_{1} \cap h_{2}\right)^{\delta(j)}}{2}\right)^{p}\right] \\
& =\frac{1}{l} \sum_{j=1}^{l}\left[\left(\frac{\left(\max \left\{h_{1}^{\delta(j)}, h_{2}^{\delta(j)}\right\}\right)^{p}+\left(\min \left\{h_{1}^{\delta(j)}, h_{2}^{\delta(j)}\right\}\right)^{p}}{2}\right)-\left(\frac{\max \left\{h_{1}^{\delta(j)}, h_{2}^{\delta(j)}\right\}+\min \left\{h_{1}^{\delta(j)}, h_{2}^{\delta(j)}\right\}}{2}\right)^{p}\right] .
\end{aligned}
$$

In the case where $h_{1}^{\delta(j)} \leq h_{2}^{\delta(j)}$, we easily conclude that and hence,

$$
\begin{aligned}
& \max \left\{h_{1}^{\delta(j)}, h_{2}^{\delta(j)}\right\}=h_{2}^{\delta(j)}, \\
& \min \left\{h_{1}^{\delta(j)}, h_{2}^{\delta(j)}\right\}=h_{1}^{\delta(j)},
\end{aligned}
$$

$$
\operatorname{Div}_{\Gamma}\left(h_{1} \cup h_{2}, h_{1} \cap h_{2}\right)=\frac{1}{l} \sum_{j=1}^{l}\left[\left(\frac{\left(h_{2}^{\delta(j)}\right)^{p}+\left(h_{1}^{\delta(j)}\right)^{p}}{2}\right)-\left(\frac{h_{2}^{\delta(j)}+h_{1}^{\delta(j)}}{2}\right)^{p}\right]=\operatorname{Div}_{\Gamma}\left(h_{1}, h_{2}\right) .
$$

For the other case, that is, $h_{1}^{\delta(j)} \geq h_{2}^{\delta(j)}$, we conclude again the latter result. Therefore, we have

$$
\operatorname{Div}_{\Gamma}\left(h_{1} \cup h_{2}, h_{1} \cap h_{2}\right)=\operatorname{Div}_{\Gamma}\left(h_{1}, h_{2}\right) .
$$

The proof of relation (22): 


$$
\begin{aligned}
& \operatorname{Div}_{\Gamma}\left(h_{1} \cup h_{2}, h_{3}\right)=\frac{1}{l} \sum_{j=1}^{l}\left[\left(\frac{\left(\left(h_{1} \cup h_{2}\right)^{\delta(j)}\right)^{p}+\left(h_{3}^{\delta(j)}\right)^{p}}{2}\right)-\left(\frac{\left(h_{1} \cup h_{2}\right)^{\delta(j)}+h_{3}^{\delta(j)}}{2}\right)^{p}\right] \\
& =\frac{1}{l} \sum_{j=1}^{l}\left[\left(\frac{\left(\max \left\{h_{1}^{\delta(j)}, h_{2}^{\delta(j)}\right\}\right)^{p}+\left(h_{3}^{\delta(j)}\right)^{p}}{2}\right)-\left(\frac{\max \left\{h_{1}^{\delta(j)}, h_{2}^{\delta(j)}\right\}+h_{3}^{\delta(j)}}{2}\right)^{p}\right] . \\
& \max \left\{h_{1}^{\delta(j)}, h_{2}^{\delta(j)}\right\}=h_{2}^{\delta(j)}
\end{aligned}
$$
obtained:

which gives rise to

$$
\operatorname{Div}_{\Gamma}\left(h_{1} \cup h_{2}, h_{3}\right)=\frac{1}{l} \sum_{j=1}^{l}\left[\left(\frac{\left(h_{2}^{\delta(j)}\right)^{p}+\left(h_{3}^{\delta(j)}\right)^{p}}{2}\right)-\left(\frac{h_{2}^{\delta(j)}+h_{3}^{\delta(j)}}{2}\right)^{p}\right]=\operatorname{Div}_{\Gamma}\left(h_{2}, h_{3}\right)
$$

For the other case, that is, $h_{1}^{\delta(j)} \geq h_{2}^{\delta(j)}$, we achieve that

$$
\operatorname{Div}_{\Gamma}\left(h_{1} \cup h_{2}, h_{3}\right)=\frac{1}{l} \sum_{j=1}^{l}\left[\left(\frac{\left(h_{1}^{\delta(j)}\right)^{p}+\left(h_{3}^{\delta(j)}\right)^{p}}{2}\right)-\left(\frac{h_{1}^{\delta(j)}+h_{3}^{\delta(j)}}{2}\right)^{p}\right]=\operatorname{Div}_{\Gamma}\left(h_{1}, h_{3}\right) .
$$

Now, it follows from (30) and (31) that

$\operatorname{Div}_{\Gamma}\left(h_{1} \cup h_{2}, h_{3}\right)=\frac{1}{2}\left(\operatorname{Div}_{\Gamma}\left(h_{1}, h_{3}\right)+\operatorname{Div}_{\Gamma}\left(h_{2}, h_{3}\right)\right)$.

The proof of relation (23): the justification of relation (23) is similar to that of relation (22).

Theorem 4. Suppose that $h_{1}=\left\{h_{1}^{\delta(j)} \mid j=1, \ldots, l\right\}$, $h_{2}=\left\{h_{2}^{\delta(j)} \mid j=1, \ldots, l\right\}$, and $h_{3}=\left\{h_{3}^{\delta(j)} \mid j=1, \ldots, l\right\}$ are three length-unified HFEs, and the formula Div ${ }_{\Gamma}\left(h_{1}, h_{2}\right)$ given by
(8) presents a divergence measure. Then, the following inequalities hold true:

$$
\begin{aligned}
& \operatorname{Div}_{\Gamma}\left(h_{1} \cup h_{3}, h_{2} \cup h_{3}\right) \leq \operatorname{Div}_{\Gamma}\left(h_{1}, h_{2}\right), \\
& \operatorname{Div}_{\Gamma}\left(h_{1} \cap h_{3}, h_{2} \cap h_{3}\right) \leq \operatorname{Div}_{\Gamma}\left(h_{1}, h_{2}\right) .
\end{aligned}
$$

Proof. For any $j=1, \ldots, l$ and $p \geq 1$, we offer the following proofs.

The proof of relation (33):

$$
\begin{aligned}
\operatorname{Di} v_{\Gamma}\left(h_{1} \cup h_{3}, h_{2} \cup h_{3}\right) & =\frac{1}{l} \sum_{j=1}^{l}\left[\left(\frac{\left(\left(h_{1} \cup h_{3}\right)^{\delta(j)}\right)^{p}+\left(\left(h_{2} \cup h_{3}\right)^{\delta(j)}\right)^{p}}{2}\right)-\left(\frac{\left(h_{1} \cup h_{3}\right)^{\delta(j)}+\left(h_{2} \cup h_{3}\right)^{\delta(j)}}{2}\right)^{p}\right] \\
& =\frac{1}{l} \sum_{j=1}^{l}\left[\left(\frac{\left(\max \left\{h_{1}^{\delta(j)}, h_{3}^{\delta(j)}\right\}\right)^{p}+\left(\max \left\{h_{2}^{\delta(j)}, h_{3}^{\delta(j)}\right\}\right)^{p}}{2}\right)-\left(\frac{\max \left\{h_{1}^{\delta(j)}, h_{3}^{\delta(j)}\right\}+\max \left\{h_{2}^{\delta(j)}, h_{3}^{\delta(j)}\right\}}{2}\right)^{p}\right] .
\end{aligned}
$$

Accordingly, all the possible cases are as follows:

$$
\begin{aligned}
& h_{2}^{\delta(j)} \leq h_{3}^{\delta(j)} \leq h_{1}^{\delta(j)}, \\
& h_{3}^{\delta(j)} \leq h_{1}^{\delta(j)} \leq h_{2}^{\delta(j)}, \\
& h_{3}^{\delta(j)} \leq h_{2}^{\delta(j)} \leq h_{1}^{\delta(j)} .
\end{aligned}
$$

From the first case to the last case which are labelled by (36)-(41), we conclude, respectively, that 


$$
\begin{aligned}
& \operatorname{Div}_{\Gamma}\left(h_{1} \cup h_{3}, h_{2} \cup h_{3}\right)=\operatorname{Div}_{\Gamma}\left(h_{3}, h_{3}\right), \\
& \operatorname{Div}_{\Gamma}\left(h_{2} \cup h_{3}, h_{2} \cup h_{3}\right)=\operatorname{Div}_{\Gamma}\left(h_{3}, h_{3}\right), \\
& \operatorname{Div}_{\Gamma}\left(h_{1} \cup h_{3}, h_{2} \cup h_{3}\right)=\operatorname{Div}_{\Gamma}\left(h_{2}, h_{3}\right), \\
& \operatorname{Div}_{\Gamma}\left(h_{2} \cup h_{3}, h_{1} \cup h_{3}\right)=\operatorname{Div}_{\Gamma}\left(h_{1}, h_{3}\right), \\
& \operatorname{Div}_{\Gamma}\left(h_{1} \cup h_{3}, h_{2} \cup h_{3}\right)=\operatorname{Div}_{\Gamma}\left(h_{1}, h_{2}\right), \\
& \operatorname{Div}_{\Gamma}\left(h_{2} \cup h_{3}, h_{1} \cup h_{3}\right)=\operatorname{Div}_{\Gamma}\left(h_{2}, h_{1}\right) .
\end{aligned}
$$

Clearly, the first case and the second case (i.e, equations (36) and (37)) give rise to $\operatorname{Div}_{\Gamma}\left(h_{3}, h_{3}\right) \leq \operatorname{Div}_{\Gamma}\left(h_{1}, h_{2}\right)$, and moreover, the third case and the fourth case (i.e, equations (38) and (39)) result in $\operatorname{Div}_{\Gamma}\left(h_{2}, h_{3}\right), \operatorname{Div}_{\Gamma}$ $\left(h_{1}, h_{3}\right) \leq \operatorname{Div}_{\Gamma}\left(h_{1}, h_{2}\right)$. Therefore, by taking all the above results into consideration, we find that

$$
\begin{aligned}
& \operatorname{Div}_{\Gamma}\left(h_{1} \cup h_{3}, h_{2} \cup h_{3}\right)=\operatorname{Div}_{\Gamma}\left(h_{3}, h_{3}\right)+\operatorname{Div}_{\Gamma}\left(h_{3}, h_{3}\right)+\operatorname{Div}_{\Gamma}\left(h_{2}, h_{3}\right) \\
& +\operatorname{Div}_{\Gamma}\left(h_{1}, h_{3}\right)+\operatorname{Div}_{\Gamma}\left(h_{1}, h_{2}\right)+\operatorname{Div}_{\Gamma}\left(h_{2}, h_{1}\right) \\
& \leq \frac{1}{6}(\underbrace{\operatorname{Div}_{\Gamma}\left(h_{1}, h_{2}\right)+\cdots+\operatorname{Div}_{\Gamma}}_{6}\left(h_{1}, h_{2}\right))=\operatorname{Div}_{\Gamma}\left(h_{1}, h_{2}\right) \text {. }
\end{aligned}
$$

The proof of relation (34): it is proved in a similar way as the proof of inequality (33).

\section{Hesitant Fuzzy Additive Ratio Assessment (HFARAS)}

In this part of contribution, we modify the framework of hesitant fuzzy additive ratio assessment (HFARAS) which was initiated by Mishra et al. [10]. They used mainly the concept of divergence measure for developing the complex multiple criteria decision-making methodology. This work concentrates more on the methodology of Mishra et al. [10], in which a class of fruitful divergence measures for HFSs is employed instead. The resulted methodology is constituted by the following steps:

Step 1 . We initially form each individual decision matrix corresponding to the evaluation of experts $\epsilon_{k}(k=1, \ldots, r)$ as follows:

$$
{ }^{\epsilon_{k}} D=\left[\begin{array}{cccc}
C_{1} & C_{2} & \ldots & C_{n} \\
A_{1} & { }^{\epsilon_{k}} h_{11} & \epsilon_{k} h_{12} & { }^{\epsilon_{k}} h_{1 n} \\
A_{2} & { }^{\epsilon_{k}} h_{21} & { }^{\epsilon_{k}} h_{22} & { }^{\epsilon_{k}} h_{2 n} \\
\vdots & \vdots & \vdots & \vdots \\
A_{m} & { }^{\epsilon_{k}} h_{m 1} & { }^{\epsilon_{k}} h_{m 2} & { }^{\epsilon_{k}} h_{m n}
\end{array}\right],
$$

in which the HFS array ${ }^{\epsilon_{k}} h_{i j}(i=1, \ldots, m, j=1, \ldots, n)$ indicates the rating of alternative $A_{i}$ corresponding to the criterion $C_{j}$ with the weight of $\omega_{j}$.

By the way, the degree of significant for each expert $\epsilon_{k}$ $(k=1, \ldots, r)$ is computed by the use of

$$
\varpi_{\epsilon_{k}}=\frac{\sum_{t=1}^{l} \epsilon_{k} h_{i j}^{\delta(t)}}{\sum_{k=1}^{r}\left(\sum_{t=1}^{l} \epsilon_{k} h_{i j}^{\delta(t)}\right)}, \quad(i=1, \ldots, m, j=1, \ldots, n),
$$

where ${ }^{\varepsilon_{k}} h_{i j}=\left\{\varepsilon_{k} h_{i j}^{\delta(t)} \mid t=1, \ldots, l\right\}$. Furthermore, it is easily seen that $\Phi_{\epsilon_{k}} \geq 0$ and $\sum_{k=1}^{r} \Phi_{\epsilon_{k}}=1$.

Step 2. We aggregate all the individual decision matrices into the aggregated matrix:

$$
D=\left[\begin{array}{cccc}
C_{1} & C_{2} & \cdots & C_{n} \\
A_{1} & h_{11} & h_{12} & h_{1 n} \\
A_{2} & h_{21} & h_{22} & h_{2 n} \\
\vdots & \vdots & \vdots & \vdots \\
A_{m} & h_{m 1} & h_{m 2} & h_{m n}
\end{array}\right],
$$

in which

$$
h_{i j}=\left\{U_{\epsilon_{1} h_{i j}^{\delta(t)} \epsilon^{\epsilon_{1}} h_{i j}, \ldots,{ }_{r} h_{i j}^{\delta(t)} \epsilon_{r} h_{i j}}\left\{1-\prod_{k=1}^{r}\left(1-{ }^{\epsilon_{k}} h_{i j}^{\delta(t)}\right)^{\omega_{\epsilon_{k}}}\right\} \mid t=1, \ldots, l\right\},
$$


for any $i=1, \ldots, m$ and $j=1, \ldots, n$.

4.1. The Intermediate Steps. Now, if we use the intermediate steps, then the weight of criteria is to be computed based on the two parameters: rationality degree and importance degree.

\subsection{The Rationality Degree}

(1) If we employ a divergence measure Div, we then find the support degree between the criteria $C_{j}$ and $C_{l}$ as

$$
\begin{aligned}
& S\left(h_{i j}, h_{i l}\right)=1-\operatorname{Div}\left(h_{i j}, h_{i l}\right), \\
& (i=1, \ldots, m, j, l=1, \ldots, n, j \neq l) .
\end{aligned}
$$

(2) Using the support degree $S$, we are able to calculate the total support degree,

$$
\begin{aligned}
& T S\left(h_{i j}\right)=\sum_{l=1, l=j}^{n} S\left(h_{i j}, h_{i l}\right), \\
& (i=1, \ldots, m, j, l=1, \ldots, n),
\end{aligned}
$$

for any $h_{i j}$ over the criteria $C_{j}$.

(3) The utilization of total support degree TS leads to the rationality degree

$$
\begin{array}{r}
R_{j}=\frac{1}{m} \sum_{i=1}^{m} T S\left(h_{i j}\right), \\
(j=1, \ldots, n),
\end{array}
$$

in which $0 \leq R_{j} \leq 1$.

(4) By using the rationality degree $R_{j}$, we attain the overall rationality degree

$$
O R_{j}=\frac{R_{j}}{\sum_{j=1}^{n} R_{j}}, \quad(j=1, \ldots, n),
$$

where $0 \leq O R_{j} \leq 1$

\subsection{The Importance Degree}

(1) We calculate the individual importance degree matrix $\epsilon_{k} I$ as follows:

$$
{ }^{\epsilon_{k}} I=\left[\begin{array}{cccc}
C_{1} & C_{2} & \cdots & C_{n} \\
\epsilon_{1} & \epsilon_{1} I_{1} & { }^{\epsilon_{1}} I_{2} & { }^{\epsilon_{1}} I_{n} \\
\epsilon_{2} & { }^{\epsilon_{2}} I_{1} & { }^{\epsilon_{2}} I_{2} & { }^{\epsilon_{2}} I_{n} \\
\vdots & \vdots & \vdots & \vdots \\
\epsilon_{r} & \epsilon_{r} I_{1} & { }^{\epsilon_{r}} I_{2} & { }^{\epsilon_{r}} h_{n}
\end{array}\right],
$$

where ${ }^{\epsilon_{k}} I_{j}$ denotes the importance degree of criterion $C_{j}$ given by the $k^{\text {th }}$ expert.

Now, all the individual importance degree matrices can be aggregated into the matrix:

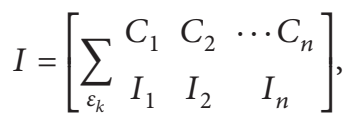

in which

$$
I_{j}=\left\{U_{\epsilon_{1} I_{j}^{\delta(t)} \in \epsilon_{1}^{\epsilon_{1}} I_{j}, \ldots,{ }_{r} I_{j}^{\delta(t)} \in \epsilon_{r} I_{j}}\left\{1-\prod_{k=1}^{r}\left(1-{ }^{\epsilon_{k}} I_{j}^{\delta(t)}\right)^{\Phi_{\epsilon_{k}}}\right\} \mid t=1, \ldots, l\right\},
$$

for any $j=1, \ldots, n$.

(2) The utilization of aggregated degree $I_{j}$ leads to the overall importance degree:

$$
O I_{j}=\frac{s\left(I_{j}\right)}{\sum_{j=1}^{n} s\left(I_{j}\right)}, \quad(j=1, \ldots, n),
$$

where $s$ denotes the score function given by (2), and moreover, $0 \leq O I_{j} \leq 1$.

Now, with the parameters of overall rationality degree $O R_{j}$ and overall importance degree $O I_{j}$ given, respectively, by (51) and (55), it derives the subjective weights of criteria as

$$
\omega_{j}=\theta O R_{j}+(1-\theta) O I_{j}, \quad(j=1, \ldots, n),
$$

where $0 \leq \theta \leq 1$ indicates the adjustment coefficient.

It is worthwhile to mention that the coefficient $\theta$ is chosen in accordance with the actual demand of decision maker, that is, the maximum value of $\theta$ stands for the superior influence of rationality degree of criteria in the assessment, and the minimum value of $\theta$ indicates the lesser influence of importance degree of criteria.

Step 3. We evaluate the $j^{\text {th }}$ element of optimal significance rating by the help of

$$
h_{O}^{j}= \begin{cases}\max _{1 \leq i \leq m}\left\{h_{i j}\right\}, & j \in C_{\text {benefit }}, \\ \min _{1 \leq i \leq m}\left\{h_{i j}\right\}, & j \in C_{\text {cost }}\end{cases}
$$

for $j=1, \ldots, n$, which results in the optimal significance rating $h_{O}=\sum_{j=1}^{n} h_{O}^{j}$.

Step 4. We are able to normalize each array of aggregated hesitant fuzzy decision matrix by using the transformation 


$$
{ }^{\aleph} h_{i j}= \begin{cases}\frac{h_{i j}}{\max _{1 \leq i \leq m}\left\{s\left(h_{i j}\right)\right\}}, & j \in C_{\text {benefit }}, \\ 1-\frac{h_{i j}}{\max _{1 \leq i \leq m}\left\{s\left(h_{i j}\right)\right\}}, & j \in C_{\text {cost }},\end{cases}
$$

where $s$ denotes the score function given by (2).

Step 5. We calculate the weighted normalized form of decision matrix as

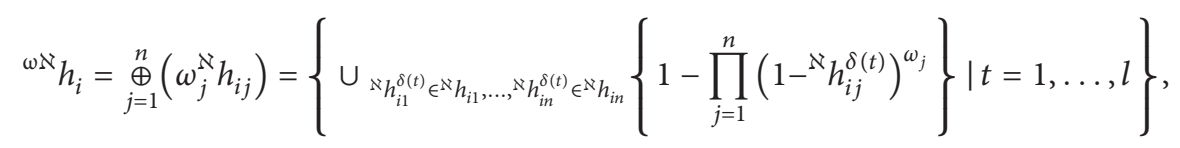

for any $i=1, \ldots, m$.

Step 6. We obtain the overall performance rating in terms of

$$
O P_{i}=s\left({ }^{\omega \aleph} h_{i}\right),(i=1, \ldots, m),
$$

in which $s$ stands for the score function given by (2).

With the help of parameter $O P_{i}$, we can estimate the preference of options. That means that the greatest value of $O P_{i}$ specifies the best option, and its lowest value characterizes the worst one.

However, besides the above selection option, we may assess the optimal option in accordance with the relative impact of that option being called the utility degree and evaluated by

$$
U_{i}=\frac{O P_{i}}{h_{O}} . \quad(i=1, \ldots, m) .
$$

The largest value of $U_{i}$ determines the desirable one.

\section{Case Study of the COVID-19 Coronavirus}

COVID-19 is the most recognized and thoroughly known virus by humans in the recent times. According to the World Health Organization report on November 29, 2020, more than $62,570,316$ cases of COVID-19 across the world have been estimated which cause more than 1,466,426 deaths and $44,671,725$ recovered persons [32]. Using data from the aforementioned report, most people with COVID-19 are associated with the symptoms and signs including fever $(83 \%-99 \%)$, cough $(59 \%-82 \%)$, fatigue $(44 \%-70 \%)$, anorexia $(40 \%-84 \%)$, shortness of breath $(31 \%-40 \%)$, sputum production $(28 \%-33 \%)$, and myalgias $(11 \%-35 \%)[33,34]$.

In this contribution, we have selected five medicines to manage the critical care of COVID-19 patients [35] including LPV/RTV-IFNb $\left(A_{1}\right)$, favipiravir $\left(A_{2}\right)$, LPV/RTV $\left(A_{3}\right)$, remdesivir $\left(A_{4}\right)$, and hydroxychloroquine $\left(A_{5}\right)$.

However, what is to be noted here is that the antiviral drugs should be considered not only for their impact on signs but also for their probable side effects and performance. To do this task, we have chosen the following parameters: anorexia $\left(C_{1}\right)$, cough $\left(C_{2}\right)$, fatigue $\left(C_{3}\right)$, fever $\left(C_{4}\right)$, myalgia $\left(C_{5}\right)$, shortness of breath $\left(C_{6}\right)$, and sputum production $\left(C_{7}\right)[15,17,33]$. In order to select an ideal drug, Mishra et al. [10] presented the assessment values in the form of linguistic variables together with hesitant fuzzy preference degrees as those given in Table 1.

Now, if we employ the algorithm of hesitant fuzzy additive ratio assessment (HFARAS) presented thoroughly in Section 4 to the abovementioned problem, then each step of algorithm can be carried out as follows.

Step 7. On the basis of data given in Table 1 and relation (45), we get the degree of significant $\Phi_{\epsilon_{k}}$ for each expert $\epsilon_{k}$ $(k=1,2,3)$ as

$$
\varpi_{\epsilon_{1}}=0.3372, \oplus_{\epsilon_{2}}=0.2674, \Phi_{\epsilon_{3}}=0.3953 .
$$

Moreover, Table 2 provides the evaluation of five drugs performance in accordance with the seven criteria for each of three experts.

Step 8. The opinions of three experts are aggregated using formula (47), and this leads to results expressible in the form given in Table 3.

5.1. Comparison of Divergence-Initiated Weights. In this part of Section 5, we are interested to perform a comparison between the weight values concluded from the proposed and the exiting divergence measures $[19,36]$ to demonstrate more capabilities of the proposed ones.

Let $h_{1}=\left\{h_{1}^{\delta(j)} \mid j=1, \ldots, l\right\}$ and $h_{2}=\left\{h_{2}^{\delta(j)} \mid j=1, \ldots, l\right\}$ be two length-unified HFEs. Mishra et al. [19] and Mishra et al. [36] introduced, respectively, the exponential form of HFE divergence measures: 
TABLE 1: The assessment ratings of criteria.

\begin{tabular}{lr}
\hline Linguistic variable & Hesitant preference degree \\
\hline Extremely preferred (EP) & $(0.90,1.00)$ \\
Strongly preferred (SP) & $(0.80,0.90)$ \\
Preferred (P) & $(0.65,0.80)$ \\
Medium (M) & $(0.50,0.65)$ \\
Undesirable (U) & $(0.35,0.50)$ \\
Strongly undesirable (SU) & $(0.20,0.35)$ \\
Extremely undesirable (EU) & $(0.00,0.20)$ \\
\hline
\end{tabular}

TABLE 2: The linguistic variable-based data of the evaluation matrix.

\begin{tabular}{|c|c|c|c|c|c|c|}
\hline \multirow{2}{*}{ Criteria } & \multirow{2}{*}{ Experts } & \multicolumn{5}{|c|}{ Alternatives } \\
\hline & & A1 & $\mathrm{A} 2$ & A3 & $\mathrm{A} 4$ & A5 \\
\hline \multirow{3}{*}{$\mathrm{C} 1$} & $\epsilon 1$ & $\mathrm{P}$ & $\mathrm{M}$ & $\mathrm{M}$ & SP & $M$ \\
\hline & $\epsilon 2$ & $\mathrm{M}$ & $\mathrm{P}$ & SP & SM & $\mathrm{P}$ \\
\hline & $\epsilon 3$ & $\mathrm{M}$ & $\mathrm{P}$ & M & SP & M \\
\hline \multirow{3}{*}{$\mathrm{C} 2$} & $\epsilon 1$ & $\mathrm{M}$ & $\mathrm{P}$ & $\mathrm{P}$ & $\mathrm{P}$ & $\mathrm{P}$ \\
\hline & $\epsilon 2$ & $\mathrm{M}$ & $\mathrm{M}$ & $\mathrm{M}$ & $\mathrm{P}$ & $\mathrm{P}$ \\
\hline & $\epsilon 3$ & $\mathrm{P}$ & $\mathrm{U}$ & $\mathrm{P}$ & $\mathrm{M}$ & M \\
\hline \multirow{3}{*}{$\mathrm{C} 3$} & $\epsilon 1$ & $\mathrm{U}$ & $\mathrm{M}$ & M & $\mathrm{M}$ & $\mathrm{U}$ \\
\hline & $\epsilon 2$ & $\mathrm{M}$ & $\mathrm{U}$ & $\mathrm{M}$ & $\mathrm{P}$ & $\mathrm{P}$ \\
\hline & $\epsilon 3$ & $\mathrm{M}$ & $\mathrm{P}$ & M & M & $\mathrm{P}$ \\
\hline \multirow{3}{*}{$\mathrm{C} 4$} & $\epsilon 1$ & $\mathrm{P}$ & $\mathrm{M}$ & M & $\mathrm{M}$ & $\mathrm{M}$ \\
\hline & $\epsilon 2$ & $\mathrm{M}$ & $\mathrm{M}$ & $\mathrm{P}$ & $\mathrm{M}$ & M \\
\hline & $\epsilon 3$ & $\mathrm{P}$ & $\mathrm{P}$ & $\mathrm{P}$ & $\mathrm{P}$ & $\mathrm{P}$ \\
\hline \multirow{3}{*}{ C5 } & $\epsilon 1$ & $\mathrm{M}$ & $\mathrm{M}$ & $\mathrm{U}$ & $\mathrm{M}$ & SU \\
\hline & $\epsilon 2$ & $\mathrm{U}$ & SU & $\mathrm{U}$ & $\mathrm{P}$ & M \\
\hline & $\epsilon 3$ & $\mathrm{U}$ & $\mathrm{M}$ & M & $\mathrm{P}$ & $\mathrm{P}$ \\
\hline \multirow{3}{*}{ C6 } & $\epsilon 1$ & $\mathrm{U}$ & $\mathrm{U}$ & SU & $\mathrm{P}$ & $\mathrm{U}$ \\
\hline & $\epsilon 2$ & $\mathrm{M}$ & $\mathrm{U}$ & $\mathrm{P}$ & $\mathrm{M}$ & $\mathrm{P}$ \\
\hline & $\epsilon 3$ & SU & $\mathrm{M}$ & $\mathrm{U}$ & $\mathrm{U}$ & SU \\
\hline \multirow{3}{*}{$\mathrm{C} 7$} & $\epsilon 1$ & $\mathrm{U}$ & $\mathrm{M}$ & SU & $\mathrm{P}$ & $\mathrm{M}$ \\
\hline & $\epsilon 2$ & $\mathrm{U}$ & $\mathrm{U}$ & $\mathrm{M}$ & $\mathrm{U}$ & SU \\
\hline & $\epsilon 3$ & SU & SU & $\mathrm{U}$ & $\mathrm{M}$ & $\mathrm{U}$ \\
\hline
\end{tabular}

TABle 3: The aggregated form of experts' opinions.

\begin{tabular}{lcccrr}
\hline Criteria & \multicolumn{3}{c}{ Alternatives } & A4 & A5 \\
\hline C1 & A1 & A2 & A3 & 0.804 & 0.649 \\
C2 & 0.684 & 0.666 & 0.696 & 0.604 \\
C3 & 0.608 & 0.554 & 0.633 & 0.690 \\
C4 & 0.512 & 0.572 & 0.549 & 0.624 & 0.615 \\
C5 & 0.633 & 0.608 & 0.633 & 0.729 & 0.644 \\
C6 & 0.450 & 0.476 & 0.454 & 0.600 & 0.548 \\
C7 & 0.423 & 0.454 & 0.469 & 0.604 & 0.547 \\
\hline
\end{tabular}

TABLE 4: The values of $\omega_{j}$ corresponding to the divergence measures $\operatorname{Div}_{M 3}$ and $\operatorname{Div}_{M 4}$.

\begin{tabular}{lccccccc}
\hline Criteria & \multirow{2}{*}{$\omega_{j}^{M 3}$} & $P=1.0$ & $P=1.2$ & $P=1.4$ & $P=1.6$ & $P=1.8$ & $P=2.0$ \\
\hline C1 & 0.150 & 0.1502 & 0.1503 & 0.1503 & 0.1503 & 0.1503 \\
C2 & 0.163 & 0.1629 & 0.1629 & 0.1628 & 0.1628 & 0.1628 \\
C3 & 0.85 & 0.1449 & 0.1449 & 0.1449 & 0.1449 & 0.1449 \\
C4 & 0.176 & 0.1758 & 0.1758 & 0.1758 & 0.1758 & 0.1758 \\
C5 & 0.117 & 0.1177 & 0.1177 & 0.1178 & 0.1178 & NaN \\
C6 & 0.127 & 0.1271 & 0.1271 & 0.1272 & 0.1272 & NaN \\
C7 & 0.123 & 0.1214 & 0.1213 & 0.1212 & 0.1212 & 0.1272 & NaN \\
\hline
\end{tabular}

NaN, "Not-A-Number." 


$$
\begin{aligned}
& \operatorname{Div}_{M 1}\left(\left(h_{1}, h_{2}\right)\right)=\frac{1}{l} \sum_{j=1}^{l}\left[\begin{array}{l}
1-\left(\frac{h_{1}^{\delta(j)}+h_{1}^{l-\delta(j)+1}}{2}\right) \exp \left(\frac{h_{2}^{\delta(j)}+h_{2}^{l-\delta(j)+1}-h_{1}^{\delta(j)}-h_{1}^{l-\delta(j)+1}}{2}\right)- \\
\left(\frac{2-h_{1}^{\delta(j)}-h_{1}^{l-\delta(j)+1}}{2}\right) \exp \left(\frac{h_{1}^{\delta(j)}+h_{1}^{l-\delta(j)+1}-h_{2}^{\delta(j)}-h_{2}^{l-\delta(j)+1}}{2}\right)
\end{array}\right] \\
& \frac{1}{l} \sum_{j=1}^{l}\left[\begin{array}{l}
1-\left(\frac{h_{2}^{\delta(j)}+h_{2}^{l-\delta(j)+1}}{2}\right) \exp \left(\frac{h_{1}^{\delta(j)}+h_{1}^{l-\delta(j)+1}-h_{2}^{\delta(j)}-h_{2}^{l-\delta(j)+1}}{2}\right)- \\
\left(\frac{2-h_{2}^{\delta(j)}-h_{2}^{l-\delta(j)+1}}{2}\right) \exp \left(\frac{h_{2}^{\delta(j)}+h_{2}^{l-\delta(j)+1}-h_{1}^{\delta(j)}-h_{1}^{l-\delta(j)+1}}{2}\right)
\end{array}\right], \\
& \left.\operatorname{Div}_{M 2}\left(h_{1}, h_{2}\right)=\frac{1}{l \sqrt{e}(\sqrt{e}-1)} \sum_{j=1}^{l}\left[\begin{array}{r}
\left(\frac{h_{1}^{\delta(j)}+h_{1}^{l-\delta(j)+1}+h_{2}^{\delta(j)}+h_{2}^{l-\delta(j)+1}}{4}\right) \exp \left(\frac{h_{1}^{\delta(j)}+h_{1}^{l-\delta(j)+1}+h_{2}^{\delta(j)}+h_{2}^{l-\delta(j)+1}}{4}\right)+ \\
\left(\frac{4-h_{1}^{\delta(j)}+h_{1}^{l-\delta(j)+1}+h_{2}^{\delta(j)}+h_{2}^{l-\delta(j)+1}}{4}\right) \exp \left(\frac{4-h_{1}^{\delta(j)}+h_{1}^{l-\delta(j)+1}+h_{2}^{\delta(j)}+h_{2}^{l-\delta(j)+1}}{4}\right) \\
-\frac{1}{2}\left(\frac{h_{1}^{\delta(j)}+h_{1}^{l-\delta(j)+1}}{2}\right) \exp \left(\frac{h_{1}^{\delta(j)}+h_{1}^{l-\delta(j)+1}}{2}\right)+\left(\frac{2-h_{1}^{\delta(j)}-h_{1}^{l-\delta(j)+1}}{2}\right) \exp \left(\frac{2-h_{1}^{\delta(j)}-h_{1}^{l-\delta(j)+1}}{2}\right)+ \\
\left(\frac{h_{2}^{\delta(j)}+h_{2}^{l-\delta(j)+1}}{2}\right) \exp \left(\frac{h_{2}^{\delta(j)}+h_{2}^{l-\delta(j)+1}}{2}\right)+\left(\frac{2-h_{2}^{\delta(j)}-h_{2}^{l-\delta(j)+1}}{2}\right) \exp \left(\frac{2-h_{2}^{\delta(j)}-h_{2}^{l-\delta(j)+1}}{2}\right)
\end{array}\right)\right]
\end{aligned}
$$

Before going more deeply into the definition of next existing divergence measures, we here point out that the latter measures cannot discriminate different HFEs correctly in some situations. This happens especially when a HFE contains elements with the condition

$$
h_{k}^{\delta(j)}+h_{k}^{l-\delta(j)+1}=1 \text {, }
$$

for any $j=1, \ldots, l$ and $k=1,2$. In this situation,

$$
\begin{aligned}
& \operatorname{Div}_{M 3}\left(h_{1}, h_{2}\right)=0, \\
& \operatorname{Div}_{M 4}\left(h_{1}, h_{2}\right)=0,
\end{aligned}
$$

which are not logical and give rise to inconsistent and inaccurate outcomes.

Bearing the abovementioned shortcoming of $\operatorname{Div}_{M 1}$ and $\operatorname{Div}_{M 2}$ in mind, we only examine in detail the next exiting divergence measures together with the proposed ones in the current contribution.

Now, we are going to review the following HFE divergence measures, which were, respectively, introduced by Mishra et al. [10] and Mishra et al. [20]:

$$
\operatorname{Div}_{M 3}\left(h_{1}, h_{2}\right)=\frac{1}{l(\sqrt{2}-1)} \sum_{j=1}^{l}\left[\sqrt{\left(\frac{\left(h_{1}^{\delta(j)}\right)^{2}+\left(h_{2}^{\delta(j)}\right)^{2}}{2}\right)}-\left(\frac{h_{1}^{\delta(j)}+h_{2}^{\delta(j)}}{2}\right)\right]
$$


TABLE 5: The values of $\omega_{j}$ corresponding to the proposed divergence measure $\operatorname{Div}_{\Gamma}$.

\begin{tabular}{llllllr}
\hline Criteria & & & & $\omega_{j}^{\Gamma}$ & & \\
& $P=1.0$ & $P=1.2$ & $P=1.4$ & $P=1.6$ & 0.1500 & 0.1500 \\
C1 & 0.1499 & 0.1499 & 0.1499 & 0.1630 & 0.1630 \\
C2 & 0.1630 & 0.1630 & 0.1630 & 0.1446 & 0.1446 \\
C3 & 0.1445 & 0.1446 & 0.1446 & 0.1756 & 0.1756 \\
C4 & 0.1756 & 0.1756 & 0.1756 & 0.1174 & 0.1175 \\
C5 & 0.1173 & 0.1174 & 0.1174 & 0.1268 & 0.1269 \\
C6 & 0.1267 & 0.1268 & 0.1268 & 0.1225 & 0.1747 \\
C7 & 0.1229 & 0.1228 & 0.1227 & 0.1175 \\
\hline
\end{tabular}

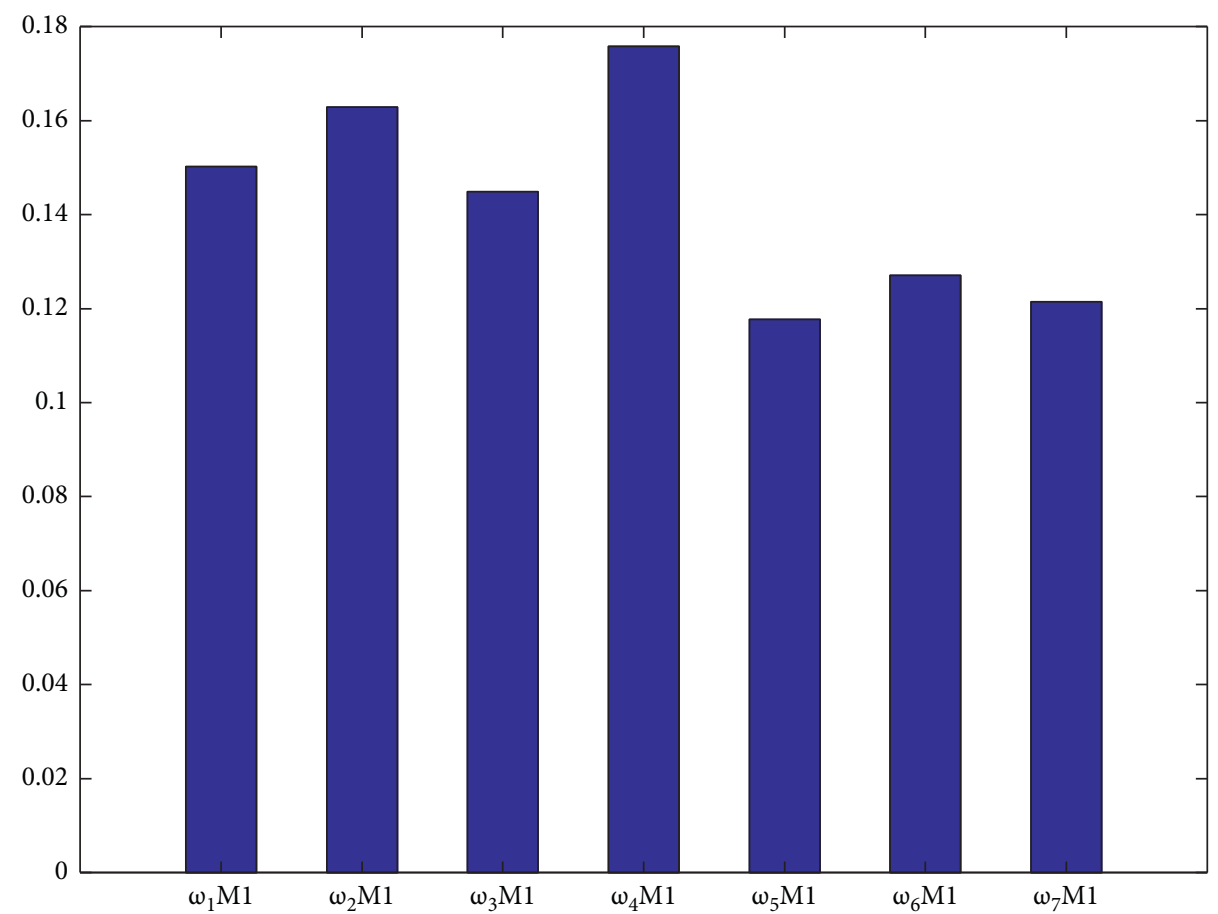

FIgURE 1: The combined criteria weights $\omega_{j}$ corresponding to the divergence measure $\operatorname{Div}_{M 3}$.

and

$$
\operatorname{Div}_{M 4}\left(h_{1}, h_{2}\right)=\frac{1}{l\left(2^{(1-(p / 2))}-1\right)} \sum_{j=1}^{l}\left[\sqrt{\left(\frac{\left(h_{1}^{\delta(j)}\right)^{2}+\left(h_{2}^{\delta(j)}\right)^{2}}{2}\right)^{p}}-\left(\frac{\left(h_{1}^{\delta(j)}\right)^{p}+\left(h_{2}^{\delta(j)}\right)^{p}}{2}\right)\right], \quad p>0 \text { and }(p \neq 2)
$$

Let us return back again to the algorithm of HFARAS presented in Section 4, and we execute the steps from Step 8 to Step 12 of that framework.

In order to perform the intermediate steps and obtaining the rationality degree and the importance degree, we incorporate the divergence measures $\operatorname{Div}_{M 3}, \operatorname{Div}_{M 4}$, and $\operatorname{Div}_{\Gamma}$ given, respectively, by (67), (68), and (8) into (48). Then, to save more space for convenient storage, we present only the combined criteria weights $\omega_{j}(j=1, \ldots, n)$ which are given by (56). All the results are, respectively, given in Table 4 and Table 5, and they are correspondingly shown in Figures 1-3.
Step 9. It is needless to say that for the three different divergence-based processes, the relation (57) returns the optimal performance rating vector of drug options in the form of

$$
\left.h_{O}^{j}\right|_{j=1} ^{7}=\{0.804,0.690,0.680,0.644,0.729,0.600,0.604\},
$$

which is extracted from Table 3.

Step 10. Since all the criteria are cost-based criteria, therefore, we do not need to normalize them. 


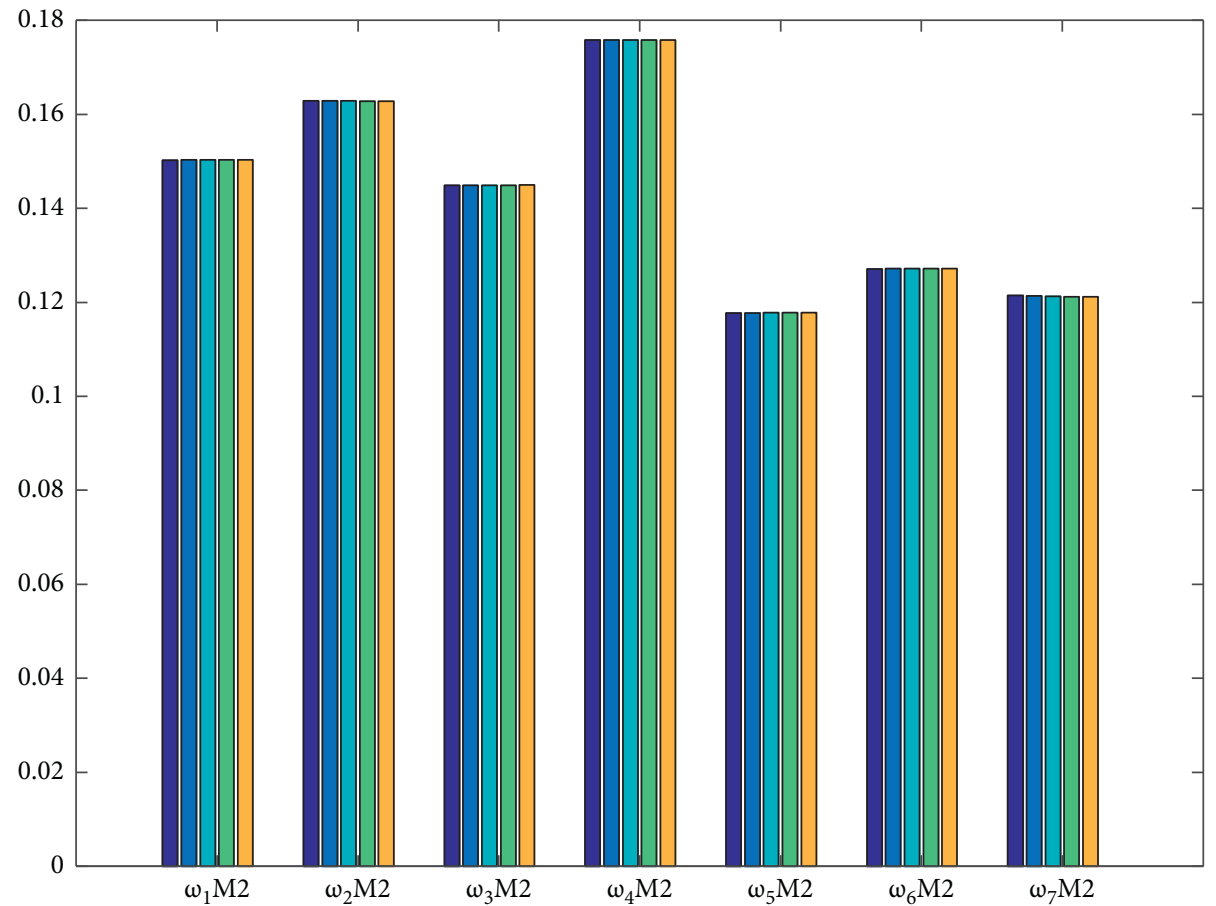

FiguRE 2: The combined criteria weights $\omega_{j}$ corresponding to the divergence measure $\operatorname{Div}_{M 4}$. The sixth column is not preserved due to "NotA-Number" value.

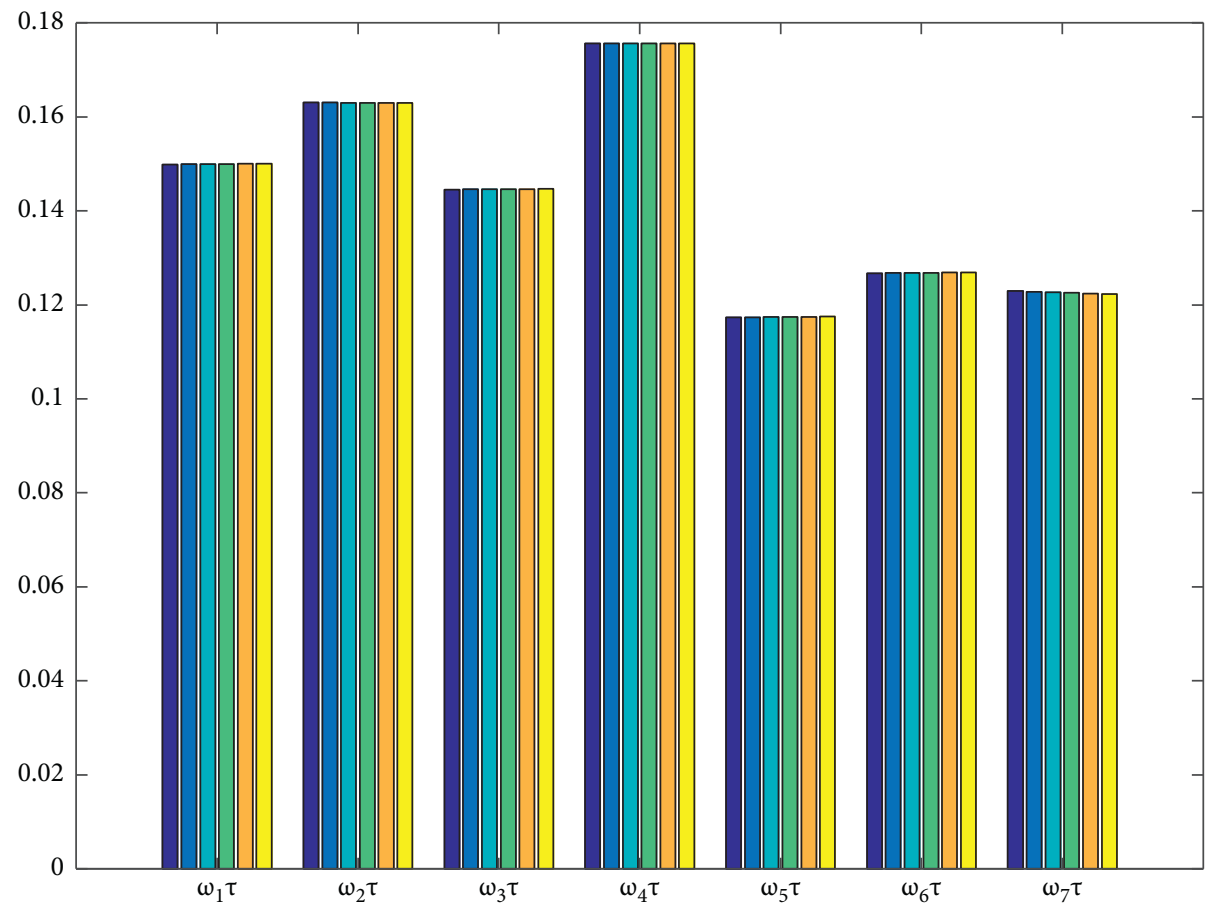

FIgURE 3: The combined criteria weights $\omega_{j}$ corresponding to the divergence measure $\operatorname{Div}_{\Gamma}$. 
TABLE 6: The weighted normalized form of decision matrix corresponding to the divergence measure $\operatorname{Div}_{M 3}$.

\begin{tabular}{|c|c|c|c|c|c|}
\hline \multirow{2}{*}{ Criteria } & \multicolumn{5}{|c|}{ Alternatives } \\
\hline & $\mathrm{A} 1$ & $\mathrm{~A} 2$ & A3 & A4 & A5 \\
\hline $\mathrm{C} 1$ & 0.1028 & 0.1001 & 0.1046 & 0.1208 & 0.0907 \\
\hline $\mathrm{C} 2$ & 0.0990 & 0.0902 & 0.1031 & 0.1057 & 0.1124 \\
\hline $\mathrm{C} 3$ & 0.0742 & 0.0829 & 0.0795 & 0.0985 & 0.0891 \\
\hline $\mathrm{C} 4$ & 0.1113 & 0.1069 & 0.1113 & 0.1097 & 0.1132 \\
\hline $\mathrm{C} 5$ & 0.0530 & 0.0560 & 0.0534 & 0.0858 & 0.0645 \\
\hline C6 & 0.0538 & 0.0577 & 0.0596 & 0.0763 & 0.0695 \\
\hline $\mathrm{C} 7$ & 0.0449 & 0.0453 & 0.0487 & 0.0733 & 0.0463 \\
\hline
\end{tabular}

TABLE 7: The weighted normalized form of decision matrix corresponding to the divergence measure $\operatorname{Div}_{M 4}($ for $p=1.0$ ).

\begin{tabular}{lccccc}
\hline Criteria & \multicolumn{3}{c}{ Alternatives } & A4 & A5 \\
\hline C1 & A1 & A2 & 0.1208 & 0.0907 \\
C2 & 0.1028 & 0.1001 & 0.1046 & 0.1057 & 0.1124 \\
C3 & 0.0990 & 0.0902 & 0.1031 & 0.0985 & 0.0891 \\
C4 & 0.0742 & 0.1069 & 0.1113 & 0.1097 & 0.1132 \\
C5 & 0.1113 & 0.0560 & 0.0534 & 0.0763 & 0.0645 \\
C6 & 0.0530 & 0.0577 & 0.0596 & 0.0733 & 0.0695 \\
C7 & 0.0538 & 0.0453 & 0.0487 & 0.0463 \\
\hline
\end{tabular}

TABLE 8: The weighted normalized form of decision matrix corresponding to the divergence measure $\operatorname{Div}_{\Gamma}($ for $p=1.0)$.

\begin{tabular}{|c|c|c|c|c|c|}
\hline \multirow{2}{*}{ Criteria } & \multicolumn{5}{|c|}{ Alternatives } \\
\hline & Al & A2 & A3 & A4 & A5 \\
\hline $\mathrm{C} 1$ & 0.1025 & 0.0998 & 0.1043 & 0.1205 & 0.0905 \\
\hline $\mathrm{C} 2$ & 0.0991 & 0.0903 & 0.1032 & 0.1058 & 0.1125 \\
\hline $\mathrm{C} 3$ & 0.0740 & 0.0827 & 0.0793 & 0.0983 & 0.0889 \\
\hline $\mathrm{C} 4$ & 0.1111 & 0.1068 & 0.1111 & 0.1096 & 0.1131 \\
\hline $\mathrm{C} 5$ & 0.0528 & 0.0558 & 0.0533 & 0.0855 & 0.0643 \\
\hline C6 & 0.0536 & 0.0575 & 0.0594 & 0.0760 & 0.0693 \\
\hline $\mathrm{C} 7$ & 0.0455 & 0.0459 & 0.0493 & 0.0742 & 0.0468 \\
\hline
\end{tabular}

The other data of divergence measures $\operatorname{Div}_{M 4}$ and $\operatorname{Div}_{\Gamma}$ for $p=1.2,1.4,1.6,1.8,2.0$ are saved and not expressed in Table 7 and Table 8 due to space limitations.

Step 11. The weighted normalized form of decision matrices corresponding to the divergence measures $\operatorname{Div}_{M 3}, \operatorname{Div}_{M 4}$, and $\operatorname{Div}_{\Gamma}$ are, respectively, given in Tables 6, 7, and 8 .

Step 12. The preference orders for the drug options in accordance with the considered divergence measures $\mathrm{Div}_{M 3}$, $\operatorname{Div}_{M 4}$, and $\operatorname{Div}_{\Gamma}$ are determined as those shown in Figures 4-6.

As can be observed, the preference order for the drug options corresponding to all three cases remains the same as follows:

$$
\begin{aligned}
& \text { Remdesivir }\left(A_{4}\right)>\text { hydroxychloroquine }\left(A_{5}\right) \\
& >\frac{\text { LPV }}{\operatorname{RTV}}\left(A_{3}\right)>\frac{\text { LPV }}{\operatorname{RTV}}-\operatorname{IFNb}\left(A_{1}\right)>\text { favipiravir }\left(A_{2}\right),
\end{aligned}
$$

and the desirable drug option is remdesivir $\left(A_{4}\right)$.

Although the final outcome of two existing divergence measures $\operatorname{Div}_{M 3}$ and $\operatorname{Div}_{M 4}$ is coincided with that of the proposed divergence measure $\operatorname{Div}_{\Gamma}$, two major issues need to be addressed here:

(i) The parametric divergence measure $\operatorname{Div}_{\Gamma}$ provides us with a class of divergence values (based on the parameter $p \geq 1$ ) wider than that of the nonparametric divergence measure $\operatorname{Div}_{M 3}$, which is contained in the former as a special case;

(ii) Both divergence measures $\operatorname{Div}_{\Gamma}$ and $\operatorname{Div}_{M 4}$ are parametric, but the latter one is meaningless when $p=2$, and this shortcoming is not going to be visible in the former one. 


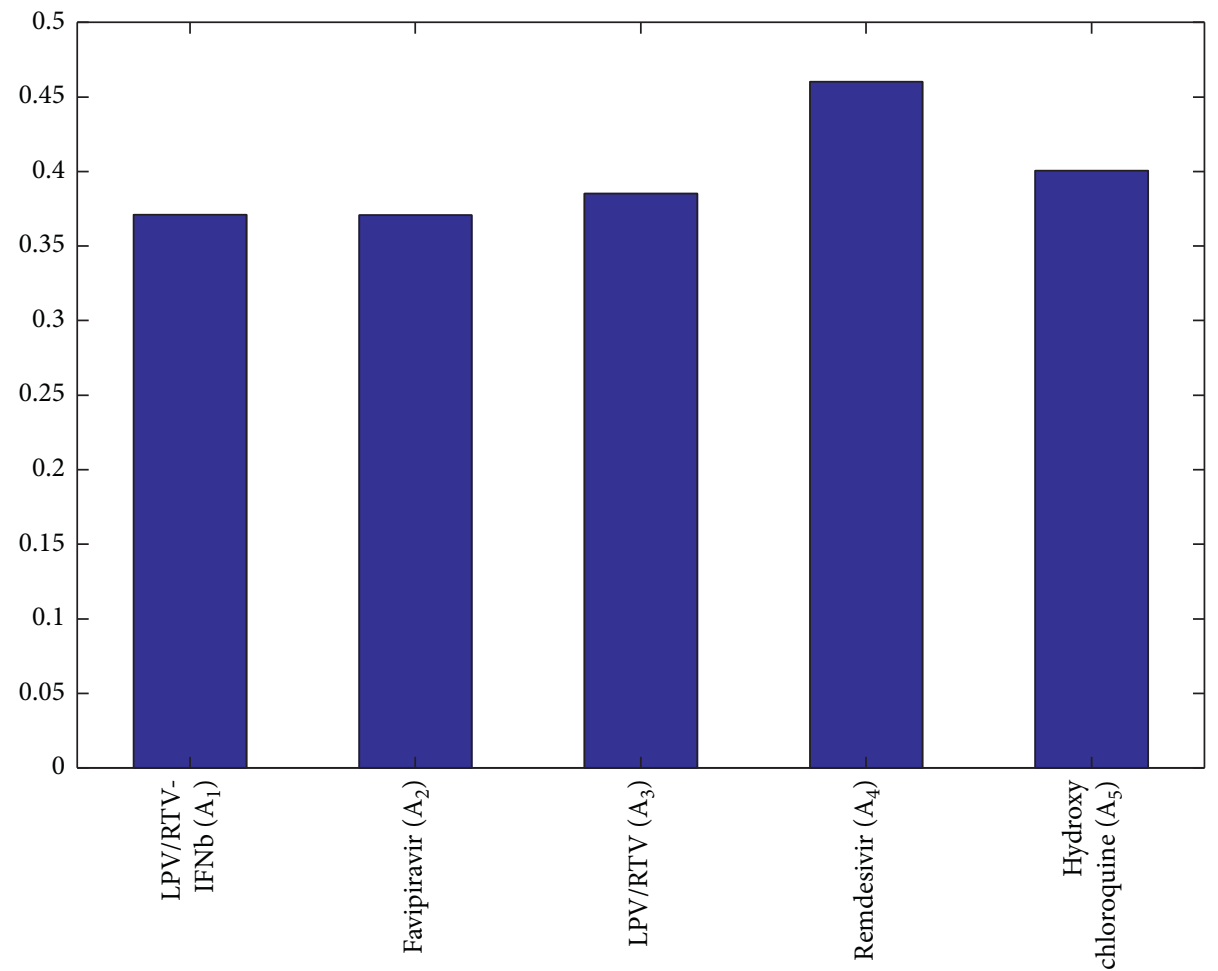

FIGURE 4: The value of alternatives corresponding to the divergence measure $\operatorname{Div}_{M 3}$.

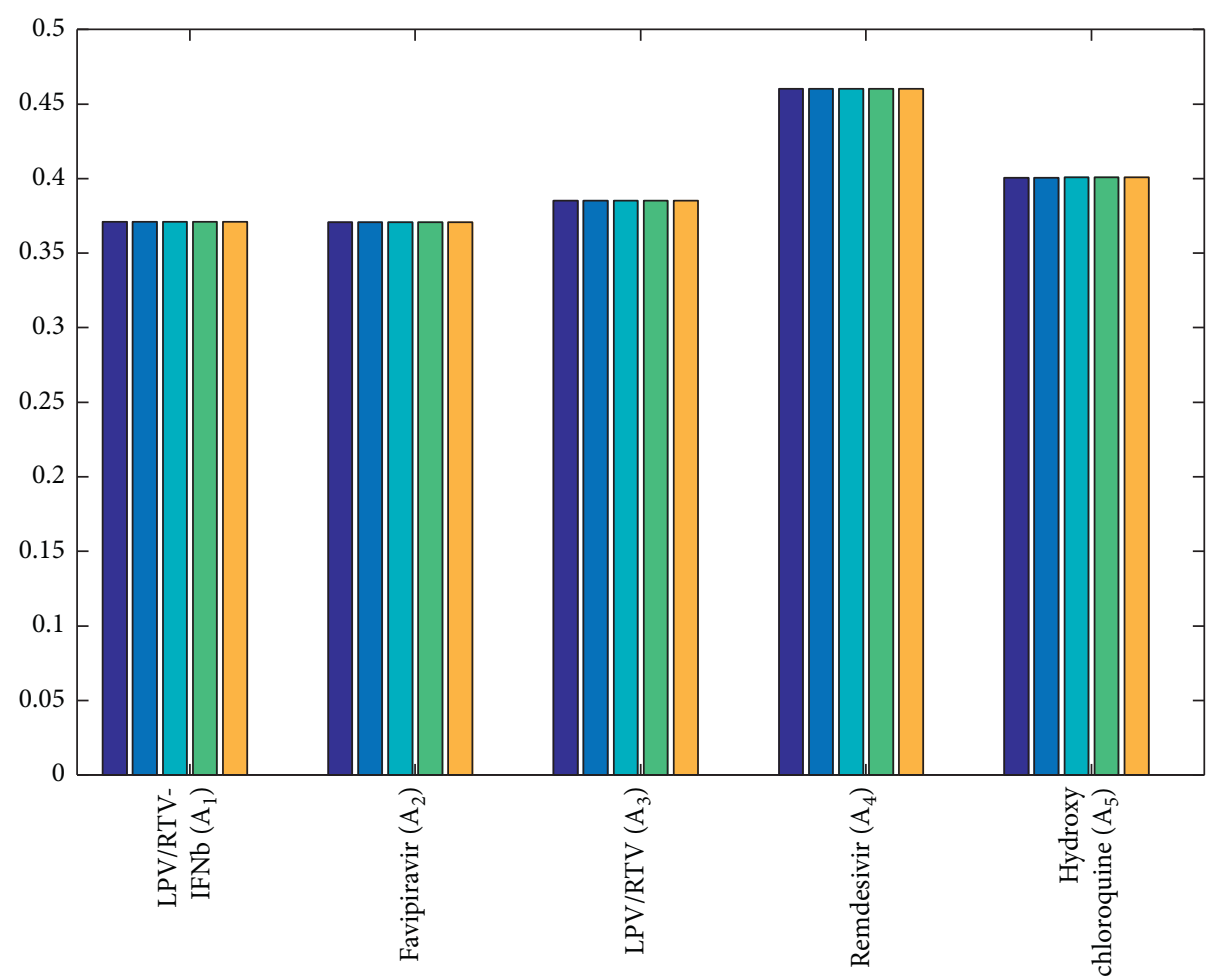

FIGURE 5: The value of alternatives corresponding to the divergence measure $\operatorname{Div}_{M 4}$. The sixth column is not preserved due to "Not-ANumber" value. 


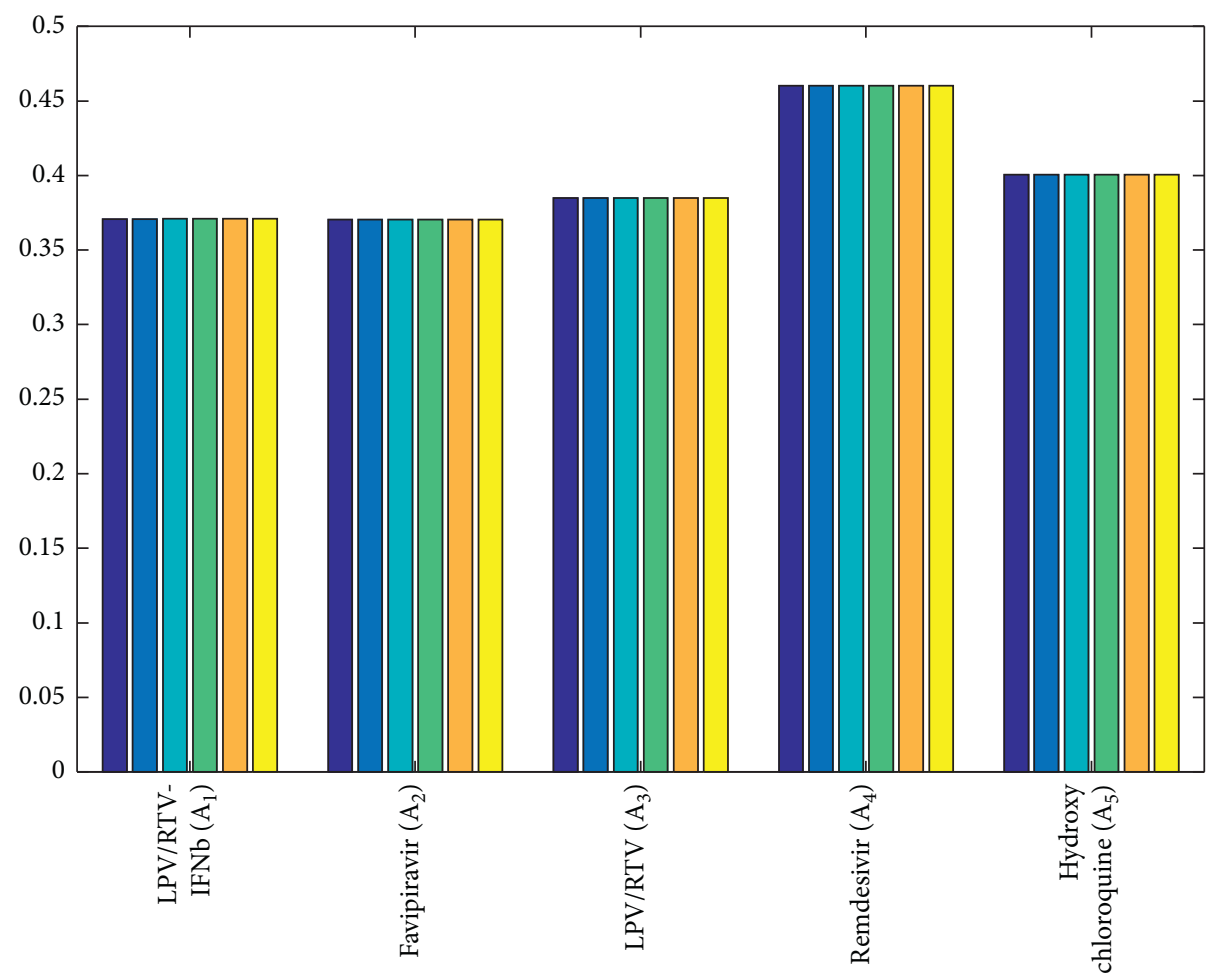

Figure 6: The value of alternatives corresponding to the divergence measure $\operatorname{Div}_{\Gamma}$.

\section{Conclusions}

This contribution offers an ARAS framework being based on the HFS divergence measure for evaluating mainly the criteria weights. The prominent role of HFS divergence measures are apparent in their parametrically and symmetrically properties.

Other main contributions of the present work are summarized as follows:

(1) Investigating of several properties for the proposed divergence measures

(2) Pointing out the counter-intuitive cases corresponding to the existing divergence measures versus the proposed ones

(3) Illustrating the validity and more applicability of the proposed divergence-based decision-making methodology

The direction of future work of this research may be focused on the other applications such as renewable energy technology selection, optimal selection of antiviral therapy for the mild symptoms of COVID-19, and other applications in the process of bid evaluation [37] and reverse logistics [38], [39].

\section{Data Availability}

The data used to support the findings of this study are available from the corresponding author upon request.

\section{Conflicts of Interest}

The author declares that there are no conflicts of interest.

\section{References}

[1] S. Lashgari, J. Antuchevičienè, A. Delavari, and O. Kheirkhah, "Using QSPM and WASPAS methods for determining outsourcing strategies," Journal of Business Economics and Management, vol. 15, no. 4, pp. 729-743, 2014.

[2] S. Narayanamoorthy, J. V. Brainy, T. Manirathinam, S. Kalaiselvan, J. V. Kureethara, and D. Kang, "An adoptable multi-criteria decision-making analysis to select a best hair mask product-extended weighted aggregated sum product assessment method," International Journal of Computational Intelligence Systems, vol. 14, no. 1, p. 160, 2021.

[3] S. Zolfaghari and S. M. Mousavi, "A new risk evaluation methodology based on FMEA, MULTIMOORA, TPOP, and interval-valued hesitant fuzzy linguistic sets with an application to healthcare industry," Kybernetes, vol. 50, no. 9, pp. 2521-2547, 2021.

[4] S. Fouladi, M. J. Ebadi, A. A. Safaei, M. Y. Bajuri, and A. Ahmadian, "Efficient deep neural networks for classification of COVID-19 based on CT images: virtualization via software defined radio," Computer Communications, vol. 176, pp. 234-248, 2021.

[5] P. Melin, J. C. Monica, D. Sanchez, and O. Castillo, "Multiple ensemble neural network models with fuzzy response aggregation for predicting COVID-19 time series: the case of Mexico," Healthcare, vol. 8, no. 2, 2020. 
[6] M. Abdel-Basst, R. Mohamed, and M. Elhoseny, "A model for the effective COVID-19 identification in uncertainty environment using primary symptoms and CT scans," Health Informatics Journal, vol. 26, no. 4, 2020.

[7] D. K. Bonilla-Aldana, Y. Holguin-Rivera, I. Cortes-Bonilla et al., "Coronavirus infections reported by ProMED, february 2000-january 2020," Travel Medicine and Infectious Disease, vol. 35, Article ID 101575, 2020.

[8] S. Ashraf and S. Abdullah, "Emergency decision support modeling for COVID-19 based on spherical fuzzy information," International Journal of Intelligent Systems, vol. 35, no. $11,2020$.

[9] C. Wu, M. Liao, M. Karatas, S. Chen, and Y. Zheng, "Realtime neural network scheduling of emergency medical mask production during COVID-19," Applied Soft Computing, vol. 97, 2020.

[10] A. R. Mishra, P. Rani, R. Krishankumar, K. S. Ravichandran, and S. Kar, "An extended fuzzy decision-making framework using hesitant fuzzy sets for the drug selection to treat the mild symptoms of Coronavirus Disease 2019 (COVID-19)," Applied Soft Computing, vol. 103, Article ID 107155, 2019.

[11] E. K. Zavadskas and Z. Turskis, "A new additive ratio assessment (aras) method in multicriteria decision-making/ naujas adityvinis kriterijų santykiụ ivertinimo metodas (aras) daugiakriteriniams uždaviniams spręsti," Technological and Economic Development of Economy, vol. 16, no. 2, pp. 159-172, 2010.

[12] Z. Turskis and E. K. Zavadskas, "A new fuzzy additive ratio assessment method (Aras-f). Case study: the analysis of fuzzy multiple criteria in order to select the logistic centers location," Transport, vol. 25, no. 4, pp. 423-432, 2010.

[13] D. Stanujkic, "Extension of the ARAS method for decisionmaking problems with interval-valued triangular fuzzy numbers," Informatica, vol. 26, no. 2, pp. 335-355, 2015.

[14] G. Büyüközkan and F. Göçer, "An extension of ARAS methodology under interval valued intuitionistic fuzzy environment for digital supply chain," Applied Soft Computing, vol. 69, pp. 634-654, 2018.

[15] G. Büyüközkan and M. Güler, "Analysis of companies' digital maturity by hesitant fuzzy linguistic MCDM methods," Journal of Intelligent and Fuzzy Systems, vol. 38, no. 1, pp. 1119-1132, 2020.

[16] M. Iordache, D. Schitea, M. Deveci, İ. Z. Akyurt, and I. Iordache, "An integrated ARAS and interval type-2 hesitant fuzzy sets method for underground site selection: seasonal hydrogen storage in salt caverns," Journal of Petroleum Science and Engineering, vol. 175, pp. 1088-1098, 2019.

[17] H. Liao, Z. Wen, and L. Liu, "Integrating BWM and ARAS under hesitant linguistic environment for digital supply chain finance supplier section," Technological and Economic Development of Economy, vol. 25, no. 6, pp. 1188-1212, 2019.

[18] E. K. Zavadskas, Z. Turskis, T. Vilutiene, and N. Lepkova, "Integrated group fuzzy multi-criteria model: case of facilities management strategy selection," Expert Systems with Applications, vol. 82, pp. 317-331, 2017.

[19] A. R. Mishra, P. Rani, and K. R. Pardasani, "Multiple-criteria decision-making for service quality selection based on Shapley COPRAS method under hesitant fuzzy sets," Granular Computing, vol. 4, no. 3, pp. 435-449, 2019.

[20] A. R. Mishra, P. Rani, R. Krishankumar, E. K. Zavadskas, F. Cavallaro, and K. S. Ravichandran, "A hesitant fuzzy combined compromise solution framework-based on discrimination measure for ranking sustainable third-party reverse logistic providers," Sustainability, vol. 13, no. 4, Article ID 2064, 2021.

[21] V. Torra, "Hesitant fuzzy sets," International Journal of Intelligent Systems, vol. 25, pp. 529-539, 2010.

[22] M. Xia and Z. Xu, "Hesitant fuzzy information aggregation in decision making," International Journal of Approximate Reasoning, vol. 52, no. 3, Article ID 52395, 2011.

[23] Z. Xu, Hesitant Fuzzy Sets Theory, Studies in Fuzziness and Soft Computing, Springer, Berlin, Germany, 2014.

[24] H. Liao, Z. Xu, and X. J. Zeng, "Hesitant fuzzy linguistic VIKOR method and its application in qualitative multiple criteria decision making," IEEE Transactions on Fuzzy Systems, vol. 23, pp. 1343-1355, 2014.

[25] B. Farhadinia, H. Liao, and E. Herrera-Viedma, "A modified class of correlation coefficients of hesitant fuzzy information," Soft Computing, vol. 25, no. 10, pp. 7009-7028, 2021.

[26] B. Farhadinia and F. Chiclana, "A decision-making methodology based on the weighted correlation coefficient in weighted extended hesitant fuzzy environments," International Journal of Intelligent Systems, vol. 36, no. 4, pp. 1485-1534, 2021.

[27] B. Farhadinia and A. Taghavi, "A Single-valued extended hesitant fuzzy score-based technique for probabilistic hesitant fuzzy multiple criteria decision-making," Complexity, vol. 2021, Article ID 2454738, 19 pages, 2021.

[28] B. Farhadinia, U. Aickelin, and H. A. Khorshidi, "Uncertainty measures for probabilistic hesitant fuzzy sets in multiple criteria decision making," International Journal of Intelligent Systems, vol. 35, no. 11, pp. 1646-1679, 2020.

[29] B. Farhadinia, "Information measures for hesitant fuzzy sets and interval-valued hesitant fuzzy sets," Information Sciences, vol. 240, pp. 129-144, 2013.

[30] R. Kadian and S. Kumar, "Renyi's-Tsallis fuzzy divergence measure and its applications to pattern recognition and fault detection," Journal of Intelligent and Fuzzy Systems, vol. 39, no. 1, pp. 731-752, 2020.

[31] R. Kumari and A. R. Mishra, "Multi-criteria COPRAS method based on parametric measures for intuitionistic fuzzy sets: application of green supplier selection," Iranian Journal of Science and Technology, Transactions of Electrical Engineering, vol. 44, no. 4, pp. 1645-1662, 2020.

[32] Worldometer, "COVID-19 Coronavirus Pandemic," 2020, http://www.worldometers.info/coronavirus/\#countries\%3C.

[33] N. Chen, M. Zhou, X. Dong et al., "Epidemiological and clinical characteristics of 99 cases of 2019 novel coronavirus pneumonia in Wuhan, China: a descriptive study," The Lancet, vol. 395, no. 10223, pp. 507-513, 2020.

[34] W.-J. Guan, Z. Ni, Y. Hu et al., "Clinical characteristics of coronavirus disease 2019 in China," New England Journal of Medicine, vol. 382, no. 18, pp. 1708-1720, 2020.

[35] Who, "Novel Coronavirus (2019-nCoV) Situation Reports," World Health Organization, 2020, http://www.who.int/ emergencies/diseases/novelcoronavirus-2019/situationreports/.

[36] A. R. Mishra, P. Rani, K. R. Pardasani, and A. Mardani, “A novel hesitant fuzzy WASPAS method for assessment of green supplier problem based on exponential information measures," Journal of Cleaner Production, vol. 238, 2019.

[37] Z.-S. Chen, X. Zhang, R. M. Rodríguez, W. Pedrycz, and L. Martínez, "Expertise-based bid evaluation for constructioncontractor selection with generalized comparative linguistic ELECTRE III," Automation in Construction, vol. 125, Article ID 103578, 2021. 
[38] Z.-S. Chen, X. Zhang, K. Govindan, X.-J. Wang, and K.-S. Chin, "Third-party reverse logistics provider selection: a computational semantic analysis-based multi-perspective multi-attribute decision-making approach," Expert Systems with Applications, vol. 166, Article ID 114051, 2021.

[39] V. Kersuliene and Z. Turskis, "An integrated multi-criteria group decision making process: selection of the chief accountant," Procedia Soc. Behav. Sci.vol. 110, pp. 897-904, 2014. 